\title{
APPROACHES TO THE GAS CONTROL IN UCG
}

\author{
JÁN KAČUR*, KAROL KOSTÚR \\ Institute of Control and Informatization of Production Processes, Faculty BERG, Technical University of Košice, \\ Boženy Němcovej 3, 04001 Košice, Slovak Republic \\ * corresponding author: jan.kacur@tuke.sk
}

\begin{abstract}
Underground Coal Gasification represents an alternative to the conventional coal mining. This technological approach is less expensive than the traditional mining. It is expected that coal will be an important energy source in the coming decades. The gasification process must be improved to ensure that the combustion reactions generate enough energy to heat the reactants. This can be achieved by controlling the flow of gasification agents and pressure control at the exit point of the reactor UCG. This paper aims to propose a stabilization of the air flow, which is a main gasification agent injected into the gasification process, underground temperature and concentration of $\mathrm{O}_{2}$ in syngas. Also, we propose a mechanism that could cope with uncertainties in the process of the UCG and its stabilization. The paper also presents a utilization of a discrete controller with an adaptation for stabilizing the UCG process variables. The controllers were verified on an ex-situ reactor.
\end{abstract}

KEYWORDS: UCG; syngas; controller; stabilization; ex-situ reactor; adaptation.

\section{INTRODUCTION}

Successful application of the UCG (Underground Coal Gasification) process requires integration of a wide range of technical disciplines, which explains its slow commercial acceptance. Special skills, used in the fields of chemistry, chemical engineering, geology, geotechnical engineering and geohydrology are all necessary to plan and execute a successful UCG project. Information about the process conditions must be constantly monitored and updated as the gasification process moves forward. The ideal temperatures of above ground coal gasification are about $1000{ }^{\circ} \mathrm{C}$. However, it isn't possible to achieve these temperatures in the UCG. Mainly because of the lack of control on the water influx and reactant gas flow patterns. It would be more useful to couple the UCG process models with a full scale process simulator so that the entire process can be modelled at once, rather than sequentially [1]. While it is impossible to monitor some variables of the process (e.g., temperatures in a georeactor), there are special systems that are developed for an indirect measurement of these variables. The changing conditions of the process may cause problems. For this reason the control system should be robust and able to continuously adapt to changes in the process.

\subsection{GeOlOGY}

The UCG requires an understanding of various aspects of the selected site. The geology, hydrology, mining, drilling, exploration, chemistry and thermodynamics of the gasification reactions in the cavity are important parameters for a successful operation [2]. There are many practical difficulties still to be overcome and it is already clear that the technology can only be applied to certain types of coal seams. The hydrogeology of the seam is important, since excessive ingress of water would render the process uneconomic and gas leakage into underground water supplies could represent an environmental hazard 1. Groundwater contamination around the UCG reactor is caused by dispersion and penetration of the products of the coal pyrolysis by migration of groundwater and escaped gases. During the gasification process, air or oxygen is injected with high pressure equal to or greater than the surroundings hydrostatic pressure. Some of the gas products are therefore lost to the surrounding permeable media and perhaps to overlying strata, as a result of cracks in the overburden [3]. Both air and oxygen gasification has been tried in the world. In the case of air a very low calorific value of syngas is produced, whereas with oxygen, the cost of the blast and the losses make the process very costly [4].

\subsection{Factors afFecting UCG}

Long-lasting experiments confirmed that the efficiency of gasification depends on factors such as the method of gasification, the temperature of the relevant zones, the type of oxidant, physical and chemical properties of coal, the process control, geology of coal, operating pressure, the mass and energy balance of the underground reactor and other gasification parameters [1]. The syngas can be produced using a variety of oxidants, including air and oxidation mixtures (e.g., $\mathrm{O}_{2} / \mathrm{H}_{2} \mathrm{O}, \mathrm{CO}_{2} / \mathrm{O}_{2}$ etc.). Effect of humidity on the parameters of syngas is significant an the extent of dependence is based on the coal bed. The most important performance parameter of the UCG is the calorific value of the syngas. The UCG is carried out as an auto-thermic process in which the injection of gasification agents, with the help of the injection hole in the coal bed, generates heat by the combustive reactions of the carbon. Due to the need to improve the gasification process, we must ensure that 


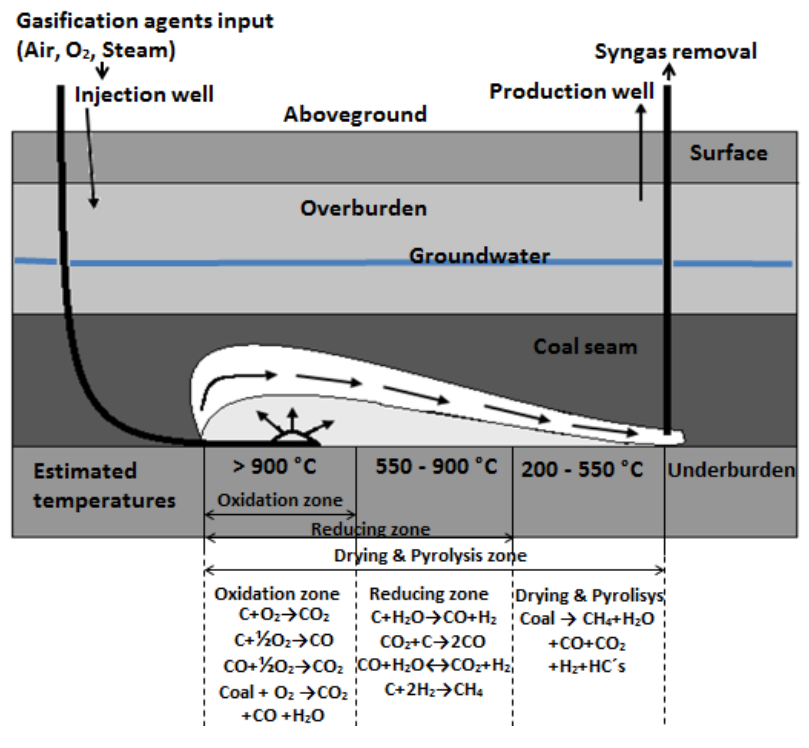

FIGURE 1. Reaction zones of UCG [5].

the combustive reactions have generated enough energy to heat the reactants and overcome the heat loss from the reactor. It is also necessary to support the rate of endothermic reactions.

Figure 1 shows the basic chemical reactions and temperatures defining the distributed reaction zones in the UCG. Injected air causes the coal to burn, which leads to exothermic processes that release heat and consume oxygen. The hot oxidized product gases migrates toward the exit borehole, passing through a reducing region where, in the absence of oxygen, they are converted to combustible gases by a number of endothermic reactions which absorb heat. The somewhat cooler, but still hot, combustible gases continue to migrate towards the exit borehole, where they cool further as they pass through a coal pyrolysis region. In this region, the coal is heated to drive off its volatile components which are tars, hydrocarbons, and other gases both combustible and non-combustible. Then, the entire gas mixture exits the seam through a production borehole.

The oxygenation of the coal increases its temperature and the desired temperature in the oxidation zone should be above $1000^{\circ} \mathrm{C}$, so that reduction can occur. After ignition of the coal in the inlet the coal seam is heated to the temperature above $600{ }^{\circ} \mathrm{C}$, hydrocarbons and gaseous components represented mainly by methane $\left(\mathrm{CH}_{4}\right)$, make up a majority of the matter burning in that region.

The formation of the plastic state of coal at temperatures up to $400{ }^{\circ} \mathrm{C}$ will not occur, because of the burn out of volatile hydrocarbons i.e., plasticizers 6 . The carbon is burnt out last and its reactivity will be high with regard to increased surface and porosity created by leaks of volatile components. Combustion products $\mathrm{CO}_{2}$ and $\mathrm{H}_{2} \mathrm{O}$ at temperatures above $1000^{\circ} \mathrm{C}$ - and flowing through a horizontal channel will create 3 zones: oxidation, reduction and distillation. In the oxidation zone, the reactions of burning gases will dominate and a temperature of generated exhaust gases range from 1000 to $1200^{\circ} \mathrm{C}$. In the reduction zone running reactions that produce $\mathrm{CO}$ and $\mathrm{H}_{2}$ and regarding the behaviour of an endothermic reactions of further coal gasification in the "reduction zone", the temperature of outgoing exhaust gases will decreases. In the distillation zone, temperatures are expected to be in a range from $130{ }^{\circ} \mathrm{C}$ (drying) to $500{ }^{\circ} \mathrm{C}$ (a release of volatile components of coal $\left(\mathrm{CH}_{4}\right.$ and $\left.\mathrm{C}_{\mathrm{n}} \mathrm{H}_{\mathrm{m}}\right)$ ). The output gas, with the temperatures above $600^{\circ} \mathrm{C}$, will be enriched by these volatile components of coal.

\subsection{Control of UCG}

The principle of automatic process control of the UCG is dependent on the nature of the information obtained from the system and the possibility to identify the controlled processes. The UCG process is difficult to identify and manage considering that the process takes place in several stages and during operation there are changes of the underground coal gasifier (e.g., cavity enlargement, shift of the combustion front, gas leaks, cracks, ground water, etc.). Usually, we can create a mathematical model from the input-output analysis. This model will represent the mathematical relationship between input and output process variables (e.g., the relationship of the oxidant flow and the syngas calorific value), but the main control issue of the UCG is a relatively large degree of uncertainty of the controlled object (i.e., coal seam), which, unlike an industrial system, was created by nature. This uncertainty can be partly reduced by a more detailed geological survey. But even by doing this, it does not guarantee elimination of uncertainty, as evidenced by long-term experience in the traditional coal mining technology.

Unfortunately, there is not much evidence of an advanced UCG control in the world. Most of works, which are published are focused on the control of the UCG with utilization of a process model. In recent times, a one-dimensional model of a coal bed was proposed for the control. This model can be used in a closed control loop with the robust Slide Mode Controller (SMC) to maintain the desired heating value of the syngas. The model is able to predict the chemical composition of the syngas based on the composition of the injected gas, and its flow and properties of coal [7, 8].

Wei and Liu 9] have proposed the principle of optimal control of coal gasification based on the Iterative Adaptive Dynamic Programming (ADP) and a learning scheme. The authors have used a neural network to construct the dynamics of the process of the coal gasification.

Some works are focused only on the prediction of output parameters of the UCG (e.g., syngas composition, temperature, or calorific value). Authors tried to use various principles of soft sensors or and thermodynamic model [10, 11]. There is little to no evidence about 
optimisation of input parameters in the UCG [12 and statistical analyses of the UCG process variables [13.

The control system of UCG should represent a set of components, modules and subsystems that are used to control the whole process. It's mechanically united as a whole to the programmable logic controller (PLC), which can perform a several control algorithms (i.e., cyclic tasks).

Based on model analysis and due to gas leaks from the cavity and the gasification channel, following cases can occur:

- danger due to an explosive concentration,

- poisoning due to increased concentrations of toxic gases,

in or near the area of active mining, but also on the surface. In order to control gas production in the underground gasifier the following means of the UCG control (see Figure 2) can be used:

- Overpressure control - the flow of the injected oxidizer is regulated.

- Under-pressure control - under-pressure is regulated by adjusting of the exhaust ventilator power.

- Combined control - the afore-mentioned are used.

Various control algorithms can be used in the feedback control, such as On-Off control (e.g., controlled switching of the compressors according to the pressure in the tank), proportional control or proportionalintegral-derivative (PID) control.

Feedback control can also be realized as a feedforward control based on the personal presence of the operator. A very widespread type of the feedback control is a regulation. The following control approaches can be implemented for the syngas production control:

- Regulation of injected oxidizer flow on desired value. By changing the volume of the flow, we can influence the course of chemical reactions during gasification and syngas quality on the outlet. The addition of $\mathrm{O}_{2}$ improves the energy effect, but the volume of $\mathrm{CO}_{2}$ increases. The air volume flow can be measured from pressure difference by an orifice plate or by the use of flowmeters. For measuring the flow rate of oxygen flowmeters should be used with a special treatment to avoid explosions. The higher rate of the injected oxidizer improves the calorific value and the rate of the gas production. Too much oxidizer can cause a negative effect, i.e., reducing the temperature in the reaction zone (cooling) and consequently also the calorific value of syngas. Therefore, there is a need to look for an optimal flow of gasification agents.

- Control of operation pressure of the injected oxidizer. The advantage of high pressure coal gasification over conventional atmospheric combustion is that the major pollutants can be economically separated from the product gas, resulting in substantial reduction in the amount of pollutants released into the environment per ton of coal processed [14.
In the future, separation and sequestration of $\mathrm{CO}_{2}$ can also lead to further significant reductions in greenhouse gas emissions. When the gasification takes place at high pressures, the reaction of hydrogen and char can become important. However, an increased injection pressure will tend to increase the gas loss from the underground reaction zone to the surrounding strata. Higher operating pressure has a positive effect on the concentration of methane and hydrogen, which ultimately affect the calorific value of the produced gas [15]. The higher operating pressure of the oxidizer displaces methane from the coal pore structure and causes cracking of coal. Also, high injection pressure can cause the loss of a gas from the underground reaction zone into the surrounding layers. These conclusions result from the analysis of a gasification in Rocky Mountain I (CRIP) and Newman Spiney [16].

- Temperature stabilization by regulated injected air. In general, stabilization means maintaining the desired value of the measured process variable to a desired value (e.g., the volume flow of injected oxidizers or oxygen concentration in the syngas) [17]. At higher temperatures, endothermic reactions (e.g., Boudoard reaction: $\mathrm{CO}_{2}+\mathrm{C}=2 \mathrm{CO}$ ) predominate the exothermic. The values of methane decrease, while the production rate of fission products, such as $\mathrm{CO}$ and $\mathrm{H}_{2}$, increases. Maximal effect of $\mathrm{CO}_{2}$ consumption is at temperatures above $1000^{\circ} \mathrm{C}$, these are the ideal theoretical conditions for the reaction of the entire amount of $\mathrm{CO}_{2}$ to $\mathrm{CO}$, assuming the presence of coal.

- Stabilization of the oxygen concentration in produced syngas with an exhaust ventilation system or by control of injected air flow. The basis is feedback control with a discrete controller. Verification of the proportional-integrating (PI) controller will be shown in the section 5.3 . It is necessary that the oxygen content of the syngas is close to zero. The components of the syngas can be measured at the outlet of the gasifier by stationary analysers based on the principle of infrared or electrochemical sensors.

- Control of burning with an exhaust fan. It is a process that uses active exhaust ventilation to ensure a complete combustion of coal in an underground coal bed. An exhaust fan is connected to a piping system that leads to the underground mine. The fan creates a vacuum and supports the smouldering of the coal. The air gets into the mine by flowing from the surface through natural cracks, crevices and also through the injection borehole. The increased airflow improves the combustion and generated gases are extracted through an output borehole by a fan. The main advantage of this system is that all the resulting gas is extracted away through a one point and with no gas losses into the surrounding layers. It was further found that the losses of heat through conduction are lower. This technique is not suitable 


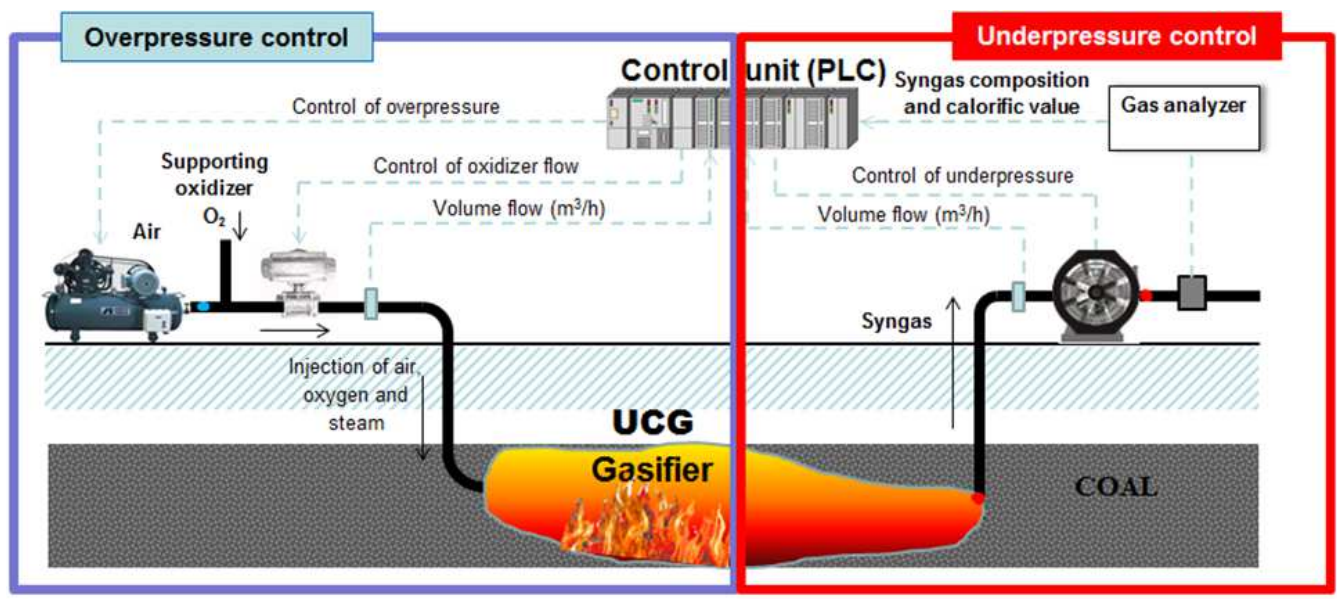

Figure 2. Basic control loops on stabilization level.

for moist and thin seams, in these conditions, the process becomes uncontrolled [18]. A controlled combustion system was applied to a superficial, thin bituminous coal seam [19].

In the considered algorithms, the utilization of an appropriate SCADA/HMI (Supervisory Control and Data Acquisition / Human Machine Interface) system is expected for the visualization of measured and controlled variables, the possibility of operative data entry and tools for operating alarms. The basic control loops can be implemented on a PLC.

Achieving the goal of the control is ensured by processing of information obtained by measuring the real output from the system (or deviation of the measured value from the set point). Such control in this case is derived directly from the current status of the system.

The following sections, will describe the feedback approach to the stabilizing of the gasification process, which is based on a digital controller.

\section{EXPERIMENTAL UCG IN LAB SCALE}

Within the experimental gasification, several control loops that were verified utilising experimental gasification equipment (i.e., ex-situ reactor, respectively syngas generator with a control system) were proposed in order to increase the performance of gasification. Figure 3 shows the base structure of gas control in the UCG. The symbol $y$ represents is the controlled variable, $w$ is the desired value of the controlled variable i.e., the set point or the reference value, $e$ is the control error, $u$ is the manipulated variable or the control variable. A basic level represents a monitoring system created within a SCADA/HMI Application Promotic. The monitoring system provides a visualization of process variables, data recording and a setup screen for adjustment of controllers. The monitoring system is implemented on a PC. The upper level represents stabilization algorithms (i.e., cyclic tasks) implemented on the PLC. Stabilizing level will stabilize inputs into the process of the UCG (e.g., pressures, flows

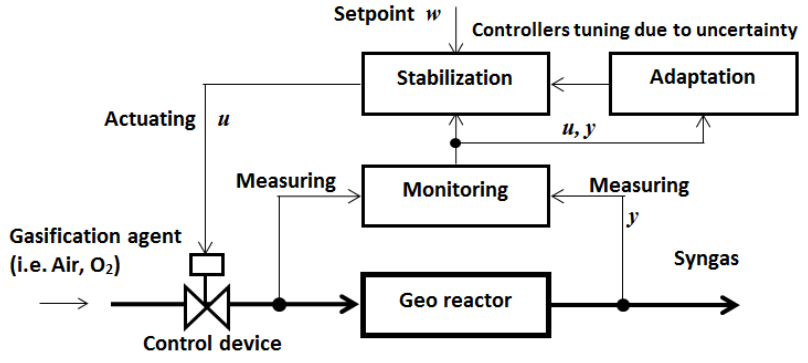

FiguRE 3. Block diagram of the feedback control

of oxidants) as well as outputs (e.g., temperature, concentration levels of oxygen in the syngas). The stabilization level is supported with an adaptation mechanism due to uncertainties in the UCG process.

The control system is based on the PLC which contains several control algorithms, which are adjusted from the environment of the monitoring system. The algorithms of the control system were programmed in an integrated development environment (IDE) of B\&R Automation Studio 2.6 with utilization of the Automation Basic Language. For gasification, the following stabilization loops were created:

- Stabilization of pressure (On-Off control) in a pressure vessel.

- Injected air flow stabilization.

- Stabilization of the temperature in the generator.

- Stabilization of the $\mathrm{O}_{2}$ concentration in the produced syngas.

Proposed control algorithms were verified on experimental gasification equipment. Two ex-situ reactors (i.e., syngas generators) for the experimental trials of the UCG were constructed. Generators were employed 'to bed' the coal, so that they may simulate the underground coal seam. The scheme on Figure 4 shows the supply system of gasification agents and the outlet system for the syngas exhaust. All relevant devices for measuring and control that were used are also shown. The air supply was supported by two 


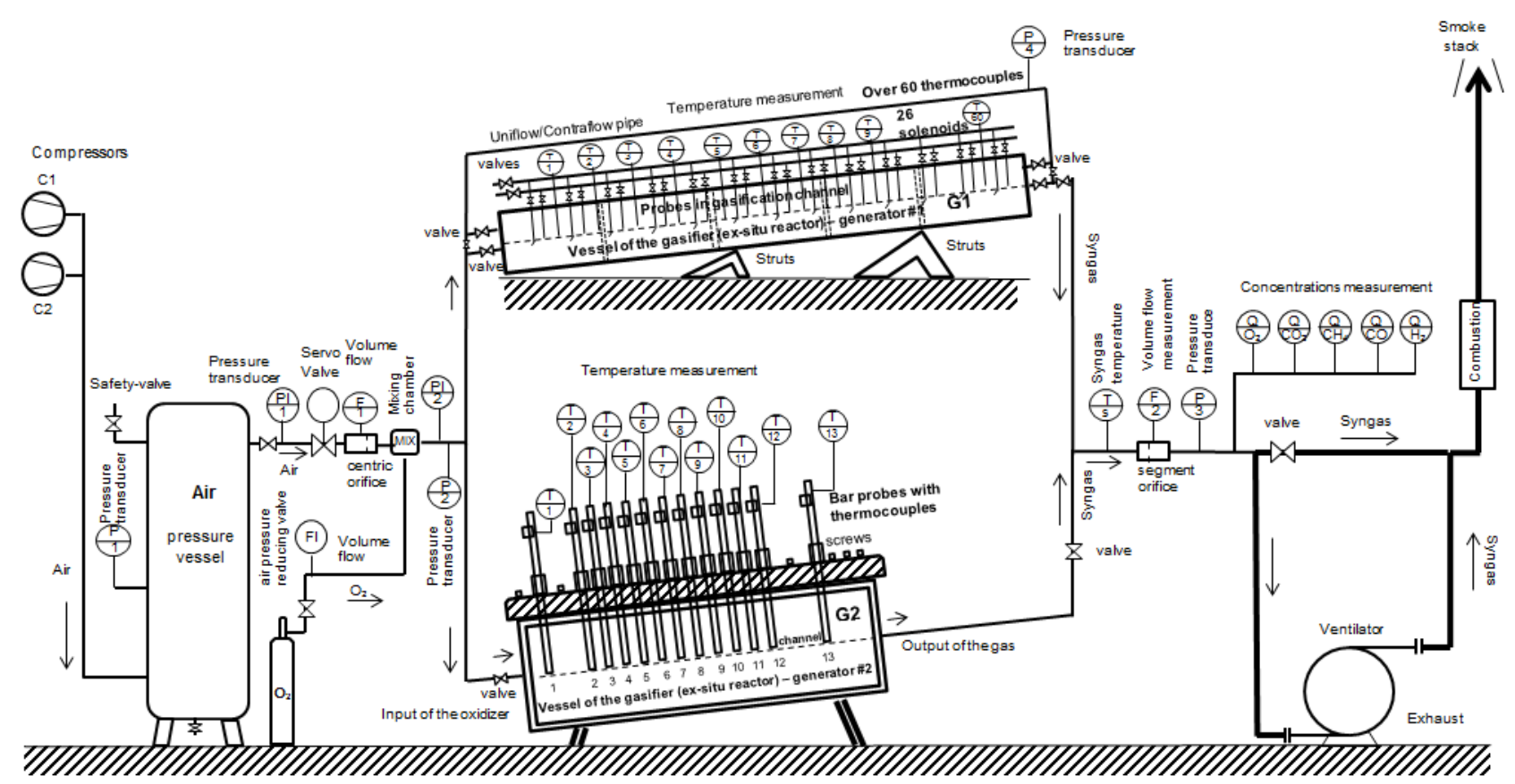

FiguRE 4. Scheme of experimental gasification equipment (modified after [20]).

compressors. The air flow was measured by utilization of a centric orifice. A servo valve was used for air flow regulation. Additional oxygen was supplied from pressure cylinders. For syngas analysis, two analysers and a calorimeter were used. For syngas exhaust, an under-pressure ventilator and a frequency inverter were used. The temperature inside the generator (i.e., in a various layers of the coal) was measured with $\mathrm{K}$ type thermocouples. The coal 'bedded into' generator represents a physical model of a real coal seam. Various models were tried (e.g., with channel, counter-flow, uni-flow, crushed coal or blocks of coal) [21. Similar gasification equipment was designed by Dobbs and Krantz 22.

The following is an overview of devices for measurement and control used in the experimental gasification:

- two piston compressor (Schneider $400 \mathrm{~V}, 10 \mathrm{bar}$ ),

- pressure vessel (Tlakon, 16 bar),

- pressure transducer on pressure vessel (Siemens, Sitrans P300, 16 bar, 4-20 mA),

- servo valve (Honeywell, 24 V),

- pressure transducer behind the servo valve (Siemens, Sitrans P, Series Z, 0-6 bar, 4-20 mA),

- centric orifice and differential pressure sensor for injected air flow measurement (Siemens, 4-20 mA),

- vortex flow meter for injected oxygen (Krohne, Microwell, VFC070, OPTISWIRL 4070/C, 4-20 mA),

- pressure transducer for air (Keyhence, 0-1 MPa, 0-5 V),

- two pressure transducers for air (Siemens, Sitrans P, Series Z, 0-10 bar, 4-20 mA),

- pressure transducer for air (Keller, 0-5 bar, 4-20 mA),
- gas analyser \#1 (Madur, CMS-7, $\mathrm{O}_{2}:$ 0-21\%, CO: 0-50\%, $\mathrm{CO}_{2}$ : 0-50\%, $\left.\mathrm{CH}_{4}: 0-100 \%, 4-20 \mathrm{~mA}\right)$,

- gas analyser \#2 (ABB, Caldos, $\mathrm{H}_{2}$ : 0-40\%, 4-20 $\mathrm{mA})$,

- portable gas analyser \#1 for CO (Testo 512),

- portable gas analyser \#2 for $\mathrm{CO}, \mathrm{O}_{2}$ and $\mathrm{CO}_{2}$ (Wohler, A97),

- calorimeter CWD 2005 (0-8 MJ/m³, 4-20 mA),

- thermocouple probes of $\mathrm{K}$ type (Omega, OMEGACLAD ${ }^{\circledR}$ sheathing, up to $\left.1335^{\circ} \mathrm{C}\right)$,

- reducing valve for injected Air, $\mathrm{O}_{2}, \mathrm{~N}_{2}$ (cleaning the analyser of $\mathrm{H}_{2}$ ), $\mathrm{CH}_{4}$ (carrier gas for calorimeter) and calibration gas,

- pressure transducer for syngas on outlet (KIMOMP52, $\pm 10000 \mathrm{~Pa}, 4-20 \mathrm{~mA}$ ),

- analyser and gas humidity probe (Madur, maPressII, RS 232),

- segment orifice and differential pressure sensor for syngas flow measurement (Siemens, 4-20 mA),

- 26 electromagnetic valves (Siemens, 24 V),

- under-pressure ventilator (Siemens, $400 \mathrm{~V})$,

- frequency inverter (Siemens, Micromaster, $400 \mathrm{~V}$, $50 \mathrm{~Hz}, 0-10 \mathrm{~V}, 4-20 \mathrm{~mA})$,

- PLC B \& R X.20 (X20CP1485, CPU Intel Celeron $400 \mathrm{MHz}, 32 \mathrm{MB}$, TCP/IP, RS232) with I/O modules $(3 \times \mathrm{DO}, 1 \times \mathrm{DI}, 4 \times \mathrm{AI}, 4 \times \mathrm{AO}, 11 \times$ thermocouple modules),

- PC, Intel P4 (Dual Core): $3 \mathrm{GHz}, 4 \mathrm{~GB}$ RAM, 1 TB HDD, $2 \times$ RS232, Ethernet TCP/IP) with SCADA/HMI system Promotic). 


\begin{tabular}{|c|c|}
\hline Parameter & Value \\
\hline Total Moisture $\mathrm{W}_{\mathrm{t}}^{\mathrm{r}}(\%)$ & 22.25 \\
\hline $\operatorname{Ash} A^{d}(\%)$ & 26.33 \\
\hline Volatiles Vdaf $(\%)$ & 60.39 \\
\hline Carbon $C^{\text {daf }}(\%)$ & 64.79 \\
\hline Hydrogen $\mathrm{H}^{\text {daf }}(\%)$ & 5.59 \\
\hline Nitrogen $\mathrm{N}^{\text {daf }}(\%)$ & 1.04 \\
\hline Calorific value $\mathrm{Q}_{\mathrm{i}}^{\text {daf }}(\mathrm{MJ} / \mathrm{kg})$ & 24.94 \\
\hline Calorific value $Q_{\mathrm{i}}^{\mathrm{d}}(\mathrm{MJ} / \mathrm{kg})$ & 18.37 \\
\hline Calorific value $\mathrm{Q}_{\mathrm{i}}^{\mathrm{r}}(\mathrm{MJ} / \mathrm{kg})$ & 13.74 \\
\hline $\operatorname{Ash} A^{r}(\%)$ & 20.47 \\
\hline Carbon $\mathrm{C}^{\mathrm{r}}(\%)$ & 37.11 \\
\hline Hydrogen $\mathrm{H}^{\mathrm{r}}(\%)$ & 3.20 \\
\hline $\mathrm{N}^{\mathrm{r}}(\%)$ & 0.59 \\
\hline $\mathrm{CaO}$ & 1.12 \\
\hline $\mathrm{MgO}(\%)$ & 0.62 \\
\hline $\mathrm{SiO}_{2}(\%)$ & 12.10 \\
\hline $\mathrm{Al}_{2} \mathrm{O}_{3}(\%)$ & 5.26 \\
\hline $\mathrm{Fe}_{2} \mathrm{O}_{3}(\%)$ & 2.89 \\
\hline $\mathrm{Na}_{2} \mathrm{O}(\%)$ & 0.14 \\
\hline $\mathrm{P}_{2} \mathrm{O}_{5}(\%)$ & 0.02 \\
\hline $\mathrm{TiO}_{2}(\%)$ & 0.17 \\
\hline $\mathrm{K}_{2} \mathrm{O}(\%)$ & 0.55 \\
\hline Volatiles $\mathrm{V}^{\mathrm{r}}(\%)$ & 34.59 \\
\hline Analytical Moisture $\mathrm{W}^{\mathrm{a}}(\%)$ & 9.56 \\
\hline Total sulphur $\mathrm{S}_{\mathrm{t}}^{\mathrm{r}}(\%)$ & 1.93 \\
\hline Sulphate sulphur $\mathrm{S}_{\mathrm{s}}^{\mathrm{r}}(\%)$ & 0.01 \\
\hline Pyritic sulphur $\mathrm{S}_{\mathrm{p}}^{\mathrm{r}}(\%)$ & 1.35 \\
\hline Organic sulphur $\mathrm{S}_{\mathrm{o}}^{\mathrm{r}}(\%)$ & 0.57 \\
\hline Oxygen $\mathrm{Q}^{\text {daf }}(\%)$ & 26.34 \\
\hline Oxygen $\mathrm{Q}^{\mathrm{d}}(\%)$ & 19.4 \\
\hline
\end{tabular}

TABLE 1. Coal sample analysis (Abbreviations: $r-$ received, d-dry, daf-dry ash-free, a-analytical) 23.

For experiments, the lignite from the mine Cigel was used. The mine Cigel belongs to the Upper Nitra coal Basin [23]. The analysis of the coal from this mine is summarized in Table 1 The analysis of the coal sample was performed in an accredited laboratory.

\section{Selection of a Suitable Site FOR IN-Situ GaSifiCATION}

For the in-situ trials of the UCG, three suitable locations were selected in Slovakia i.e., mine Cigel, Handlová and Nováky [24. It is a coal deposit region of the Hornonitrian basin. The underburden and overburden is formed by gravel, clay, coal clays and andesites [25, 26]. These are sites with a coal bed thickness of $3.2-4.5 \mathrm{~m}$ with a calorific value of the coal in the range of $10-15 \mathrm{MJ} / \mathrm{kg}$. Seams that are close to the surface and with a coal bed thickness of less than $2 \mathrm{~m}$ are unsuitable for gasification. For the comparison with the Table 1 we present some parameters of a coal from two other coal sites:

- Nováky: $\mathrm{W}_{\mathrm{t}}^{\mathrm{r}}=36 \%, \mathrm{Q}_{\mathrm{i}}^{\mathrm{r}}=11.81 \mathrm{MJ} / \mathrm{kg}, \mathrm{A}^{\mathrm{d}}=$ $21.59 \%, \mathrm{C}^{\mathrm{daf}}=65.61 \%, \mathrm{~N}^{\mathrm{daf}}=0.88 \%, \mathrm{H}^{\mathrm{daf}}=$
$5.5 \%, \mathrm{~S}_{\mathrm{t}}^{\mathrm{d}}=4.03 \%, \mathrm{~S}_{\mathrm{p}}^{\mathrm{d}}=2.84 \%, \mathrm{~S}_{\mathrm{s}}^{\mathrm{d}}=0.08 \%$ and $\mathrm{S}_{\mathrm{o}}^{\mathrm{d}}=1.12 \%$.

- Velká Trňa: $\mathrm{W}_{\mathrm{t}}^{\mathrm{r}}=1.53-14.83 \%, \mathrm{~A}^{\mathrm{r}}=11.74-39.92 \%$, $\mathrm{A}^{\mathrm{d}}=11.74-39.92 \%, \mathrm{Q}_{\mathrm{i}}^{\mathrm{r}}=14.44-27.19 \mathrm{MJ} / \mathrm{kg}, \mathrm{Q}_{\mathrm{i}}^{\mathrm{d}}=$ $14.90-31.72 \mathrm{MJ} / \mathrm{kg}, \mathrm{S}^{\mathrm{d}}=1.00-1.14 \%, \mathrm{As}^{\mathrm{d}}=100$ $560 \mathrm{ppm}, \mathrm{C}^{\mathrm{daf}}=89.83 \%, \mathrm{H}^{\mathrm{daf}}=1.34 \%, \mathrm{~N}^{\mathrm{daf}}=$ $0.77 \%, \mathrm{~S}_{\mathrm{t}}^{\mathrm{r}}=1.12 \%, \mathrm{~S}_{\mathrm{p}}^{\mathrm{r}}=0.69 \%, \mathrm{~S}_{\mathrm{o}}^{\mathrm{r}}=0.4 \%$ and $\mathrm{S}_{\mathrm{s}}^{\mathrm{r}}=0.02 \%[27$.

In addition, hydrogeological parameters such as permeability, effective porosity, and storage ratio have also been taken into account in assessing the suitability of the coal bed. These parameters are most suitable in the Cigel deposit (mining sector VII). Brown coal and lignites have significantly higher permeability and their use for the UCG is more appropriate, but due to their lower quality, we can not expect syngas with the same quality as the anthracite gas. The moisture, calorific value, sulphur and ash content affect the quality parameters of the coal in the the UCG process. Humidity affects the rate of heating of the coal and thus also the gasification time itself. The calorific value of coal directly influences the quality of the syngas. Higher sulphur content means higher costs for syngas processing. Ash content in coal is an important factor in the UCG. In UCG, the coal with a substantially higher ash content can be gasified, but the ash content affects the amount of syngas. At a high ash content, there is a risk that the coal will not be burned enough. Large amounts of groundwater in the surrounding layers can cause a decrease in the underground temperature, a reduction of the efficiency, or to the half of the UCG process. Other important properties of the coal seam that affect its use for the UCG are depth, thickness, slope and structure. Various optimal parameters and criterions for the UCG are described in literature [24, 25, 27].

The next section describes the basic form of the controller, methods of calculating the parameters of discrete controller and principles of the system identification which were used within the laboratory trials of the the UCG.

\section{Digital Feed-Back Control}

The proposed stabilization level of UCG is based on the principle of using the feedback proportionalintegral (PI) controller. The discrete controller in an incremental form was used. This controller has almost universal application, but is especially suited for towing and servo-mechanisms control. This controller can sufficiently eliminate sudden disturbances and, in most cases, improves the stability of the control loop [28]. The PI controller (2) was derived from the standard PID controller (1) 29] by omission of a derivational part. Continuous behaviour of regulation errors (i.e., deviations) was replaced by rectangles and an integral was replaced with a sum according to the practice 
presented in [17, 30]:

$$
\begin{aligned}
& u(t)=K_{\mathrm{P}}\left[e(t)+\frac{1}{T_{\mathrm{I}}} \int_{0}^{\tau} e(\tau) d \tau+T_{\mathrm{D}} \frac{d e(t)}{d t}\right], \\
& u(t)=K_{\mathrm{P}}\left[e(t)+\frac{1}{T_{\mathrm{I}}} \int_{0}^{\tau} e(\tau) d \tau\right],
\end{aligned}
$$

where $K_{\mathrm{P}}$ is the proportional gain, $T_{\mathrm{I}}$ is integral time (i.e., constant of integration), $T_{\mathrm{D}}$ is the derivative time [31], $e(t)$ is the control error (i.e., deviation) in time $t, e(t)=w(t)-y(t), w(t)$ is the desired value or so-called set point, $y(t)$ is controlled variable (e.g., measured air flow, temperature in the coal, concentration of some component in syngas), $u(t)$ is the control variable [29, 32 .

The integral is approximated by simple summation, so that a continuous function is approximated by sections $T_{0}$ of constant function (e.g., step function, rectangles). Using so-called feedback rectangular method then we get the so-called recursive, speed form of the PS (i.e., proportional-summing) controller [17]:

$$
\begin{aligned}
& \Delta u(k)= u(k)-u(k-1) \\
&=K_{\mathrm{P}}\left[e(k)+\left(\frac{T_{0}}{T_{\mathrm{I}}}-1\right) e(k-1)\right] \\
&=K_{\mathrm{P}} e(k)-K_{\mathrm{P}}\left(1-\frac{T_{0}}{T_{\mathrm{I}}}\right) e(k-1) \\
& \quad=q_{0} e(k)+q_{1} e(k-1),
\end{aligned}
$$

where $\Delta u(k)$ is an increase of the control variable, $u(k)$ is the value of the control variable in step $k$ (e.g., servo valve opening in percentage or power of the exhaust fan frequency inverter), $u(k-1)$ is the previous value of the control variable (i.e., control value from the step $k-1, e(k)$ is the control error, where $e(k)=w(k)-y(k), y(k)$ is the controlled variable (e.g., measured air flow, temperature, $\mathrm{O}_{2}$ concentration), $w(k)$ is the desired value in step $k$ (e.g., desired air flow, temperature or $\mathrm{O}_{2}$ concentration), $e(k-1)$ is previous value of control error, $q_{0}, q_{1}$ are defined parameters of the resultant discrete controller by the following substitution: $q_{0}=K_{\mathrm{P}}, q_{1}=-K_{\mathrm{P}}\left(1-T_{0} / T_{\mathrm{I}}\right), T_{0}$ is the sampling period calculated as $T_{0}=(0.25 \div 0.125) \tau_{\mathrm{d}}$ where $\tau_{\mathrm{d}}$ is the dead time or $T_{0}=(0.35 \div 1.2) T_{\mathrm{u}}$ and $T_{\mathrm{u}}$ is the delay time of the step response 30 .

The job of a control system based on the discrete PI controller is to maintain the controlled variable $y$ at its set point $w$. The discrete controller and controlled system in the form of $z$-transfer function can be simulated in a Matlab Simulink. Discrete $z$-transfer of PI controller (3) has the following form:

$$
G_{\mathrm{r}}(z)=\frac{U(z)}{E(z)}=\frac{q_{0}+q_{1} z^{-1}}{1-z^{-1}}
$$

The properties of the actuator are the most significant limitation in the choice of the sampling period (e.g., in case of servo-drives non-sensitivity and operating time).
UCG endeavours to measure several process variables that can be used for evaluation of dependencies and process behaviour (i.e., flows of gasification agents, pressures, temperatures, concentrations of gasses and calorific value of the syngas). The task of the identification process is as important as the role of the controller synthesis [33. In the case of discrete systems, the parameters of discrete ARX model (i.e., Auto-Regressive model with eXogenous inputs) (5), are directly estimated and the least-squares method as the most common method was used [34, 35]. From the identified parameters of the model, the unknown parameters of the controller can be directly calculated. The proposal of an adaptive controller is usually based on a regression ARX model of the system, which is modells the system output according the following equation [18, 36, 37]:

$$
\begin{aligned}
y(k)=-\sum_{i=1}^{n a} a_{i} y(k- & i)+\sum_{i=1}^{n b} b_{i} u(k-i) \\
& +\sum_{i=1}^{n d} d_{i} v(k-i)+e_{\mathrm{s}}(k),
\end{aligned}
$$

where $y(k)$ is the value of the output variable in the step $k$ of the sampling period $T_{0}$ i.e., at the time $t=k T_{0}$, $u(k)$ is the controller's output (i.e., control variable) in the step $k, e_{\mathrm{S}}(k)$ is the fictive noise respectively random non-measurable component, $v(k)$ is disturbance, $a_{i}, b_{i}$, $c_{i}, d_{i}$ are unknown parameters of the model, that we want to identify from measured data 33 .

The functions to calculate the parameters of the discrete model from the measured data using the Least squares method are already programmed in the mathematical program Matlab (i.e., functions: load(), $i d \operatorname{data}(), \operatorname{arx}(), f i l t())$ 38. The sampling period and order of the regression model determines the quality of the obtained model. A new identification of the controlled system is done when the proposed controller has a low quality of control or new identification is carried out at regular intervals. Identification represents the creating of the test signal $\Delta u$ — wake up the system, measurement the values of the output variable $y$ (i.e., controlled variable), editing and filtering record, and finally the mathematical model calculation in the form of a discrete $z$-transfer. For laboratory gasification these systems were controlled untill now:

- Controlled system \#1: $y$ - air flow, $u$ - the percentage of servo valve opening.

- Controlled system \#2: $y$ - coal temperature, $u$ the percentage of servo valve opening.

- Controlled system \#3: $y-\mathrm{O}_{2}$ concentration in syngas, $u$ - servo valve opening.

- Controlled system \#4: $y-\mathrm{O}_{2}(\%)$ in syngas, $u-$ exhaust fan power frequency. 


\subsection{Adaptation of Controller Due to UNCERTAINTIES IN UCG}

The vast majority of processes that occur in industrial practice has a stochastic nature. The control and identification of the UCG is often a difficult process, because the underground reactor is gradually changing (i.e., increasing cavity, moving of burning front, gas leaks through the cracks in the overburden, underground water, various anomalies etc.). It is stated as a process control in conditions of uncertainty.

In addition, the coal bed was formed by an act of nature and therefore it is different from industrial systems. Some uncertainty can be reduced by more detailed geological survey, but even that does not guarantee elimination of such uncertainty, as evidenced by the long-term experience in the traditional mining technology of coal.

Classic controllers with fixed parameters are often not appropriate for such processes, because in the case of changing parameters of the process, the control is not optimal and it leads to a loss of material, energy and a reduction of equipment life etc. One possibility of increasing the quality management of such processes is the use of adaptive control systems. In automated control the adaptive control system adapts the parameters or structure of one part of the system (i.e., controller) to change the parameters or structure of another part of the system (i.e., controlled system), so that based on chosen criterion the steady optimal behaviour of the whole system would be ensured, independent of occurring changes. Adaptation to the changing parameters or structure of the system can be done in three ways:

- Appropriate change of controller parameters.

- Changing the structure of the controller.

- Generating a suitable auxiliary input signal (adaptation by the input signal).

The addition of a feedback controller can be understood as a feedback of a higher level, which changes the controller parameters according to the quality of the control process. There are numerous approaches to the adaptive control published in the world [30].

For the calculation of the controller parameters continuously during the gasification process, the identification of regulated system was carried out repeatedly. From these new identifications, the new parameters of discrete controller were calculated. For the simulation, a discrete model of the system was used in the form of a discrete transfer function or differential equation. For the calculation of a discrete controller an applied calculation of the parameters of the continuous controller, from the dynamic characteristics of the system, was performed or parameters of a discrete controller were calculated directly from the parameters of the discrete transfer function of system. From the character of the process, which eventually changes its parameters results, it is obvious that there is a

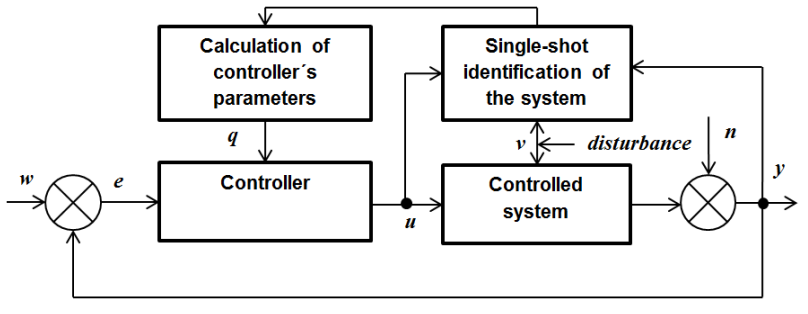

FiguRE 5. Block diagram of auto-tuning controller with repeated single-shot identification 30.

necessity to repeat the identification and calculation of controller parameters.

For assessing the quality of regulation, the quadratic criterion ISE (i.e., Integrated Squared Error) was used in the following discrete form:

$$
\mathrm{ISE}=\sum_{\mathrm{k}=1}^{\infty} e^{2}(k),
$$

where $e(k)$ is the control error in step $k$ 39].

The principled scheme of adaptation of discrete controller that was applied in gas control within experimental UCG is shown in Figure 5

\subsection{Methods for Calculating PARAmeters of A Discrete Controller}

By the term of the proposal of the controller we only understand the choice of its structure however the synthesis of the control loop, determination of the parameters of controller is based on the knowledge of the controlled system and the required criteria. In the synthesis of the control loop, it is important to convert these requirements into a mathematical formulation that is suitable for further processing. In the case of the control loop formed by the regulator and the controlled system, the structure and some parameters of the circuit are usually fully entered. The second part of the parameters and their values are optional. The synthesis then includes a determination of the appropriate type and values of controller parameters to the desired controlled system. For synthesis of the control loop, number of methods is available, they differ in their complexity and also in what regulation quality indicators result.

The choice of method depends on whether the proposed control loop is continuous or discrete. When designing discrete control loops, if they are designed to be a classic controller with a fixed structure, which is described by a transfer function or equation, the synthesis consists of a choice of the type and setting of the suitable parameters. Usually it is a numerical analogy of a continuous PID controller. In this case, the optimal parameters of a continuous PID controller are adjusted with some of the methods used for continuous control loops and parameters of the digital controller determined using the conversion equations. A possible 
way of designing discrete control loop is an approximate method based on a substitution sampler and shaper by a dead time member. Many of the known methods of continuous control loop synthesis have also its equivalent for the discrete control loops. It includes for example the method of the optimal module or the method of required model. There is also a discrete version of the Ziegler-Nichols method or methods in which the values of the delay time, rise time and gain of the controlled system are read from the behaviour of the step response of the controlled systems [40].

\subsubsection{Modified Ziegler - Nichols Open Loop Tuning Method}

Experimental setup of the parameters of a continuous PID controller, proposed by Ziegler and Nichols 41 . more than half a century ago, is still used in industrial practice. In this very famous and popular approach the PID controller parameters are calculated from the critical proportional gain $K_{\mathrm{PK}}$ and critical oscillations period $T_{\mathrm{K}}$ of the closed control loop. These critical parameters are obtained by gradually increasing the gain of the proportional controller untill the output variable of the closed control loop oscillates with a constant amplitude and the control loop is on the boundary of the stability. In this case, the poles of the closed control loop are located on the imaginary axis of the complex $s$-plane. Then we can read the critical proportional gain $K_{\mathrm{PK}}$ (i.e., ultimate gain) and from the record of the controlled variable's behaviour the critical period of oscillations $T_{\mathrm{K}}$ (i.e., ultimate period) is read. The parameters of the PI and PID controller are determined from the following equations [30, 33]:

$$
\begin{array}{rlr}
\text { PI: } & K_{\mathrm{P}}=0.5 K_{\mathrm{PK}}, & T_{\mathrm{I}}=0.83 T_{\mathrm{K}}, \\
\mathrm{PID}: & K_{\mathrm{P}}=0.6 K_{\mathrm{PK}}, & T_{\mathrm{I}}=0.5 T_{\mathrm{K}}, \\
& & T_{\mathrm{D}}=0.125 T_{\mathrm{K}}
\end{array}
$$

Disadvantages of an experimental determination of the critical parameter is that the system can be brought into an unstable state, and that a search for the stability limit in systems with large time constants is time consuming. These disadvantagesdo not have a modified method for setting the parameters of the digital controller. This method assumes that the discrete model includes the dead time to the size of $T_{0} / 2$. Dead time does not change the amplitude, but the phase shift increases linearly with the increasing frequency:

$$
\varphi=-\frac{T_{0} \omega}{2}
$$

On the critical frequency $\omega_{\mathrm{k}}$ the system has the phase shift $-\pi$ and gain $A_{\mathrm{K}}$ so that we have:

$$
A_{\mathrm{K}} K_{\mathrm{PK}}=-1
$$

Because the discreet control is by influence of the phase shift $\varphi$ caused by discretisation, which changes the critical frequency, and because at a different frequency the system has other gains; the critical gain of the system is changed too. Critical values depend on the selected sampling period $T_{0} 33$. The algorithm for calculating critical parameters for the model of the 2nd order will be presented. It assumes a discrete transfer equation of a controlled system in the form of

$$
G_{\mathrm{S}}(z)=\frac{Y(z)}{U(z)}=\frac{z^{-\mathrm{d}} B\left(z^{-1}\right)}{A\left(z^{-1}\right)}
$$

with polynomials:

$$
\begin{aligned}
& A\left(z^{-1}\right)=1+\sum_{i=1}^{2} a_{i} z^{-\mathrm{i}}=1+a_{1} z^{-1}+a_{2} z^{-2}, \\
& B\left(z^{-1}\right)=\sum_{i=1}^{2} b_{i} z^{-\mathrm{i}}=b_{1} z^{-1}+b_{2} z^{-2}
\end{aligned}
$$

where parameter $d$ is the number of steps of dead time.

Calculation of the critical gain and critical period of oscillations depends on the location of the poles on the unit circle in the complex $z$-plane 33 . For calculation of the real part of the complex conjugated pole $\alpha$ and critical control parameters $K_{\mathrm{PK}}$ and $T_{\mathrm{K}}$ the algorithm depicted in Figure 6 can be used. The algorithm can be programmed as a script in Matlab where input is represented by identified parameters $\left(a_{\mathrm{i}}, b_{\mathrm{i}}\right)$ of the model for a 2 nd order system in the form of $z$-transfer function.

The reference 30 provides an algorithm for calculating the parameters $K_{\mathrm{PK}}$ and $T_{\mathrm{K}}$ for the model of the 3rd order.

\subsubsection{Time-Optimal Control — Dead Beat METHOD}

The method of a time-optimal control solves the proposal of the common digital controller. It is a method of synthesis, according to criteria completion of the regulatory process in a few numbers of steps. The general form of the controlled system transfer is considered in the form:

$$
\begin{aligned}
& G_{\mathrm{S}}(z)=\frac{Y(z)}{U(z)} \\
& =\frac{b_{1} z^{-1}+b_{2} z^{-2}+\cdots+b_{n_{k_{\min }}}}{1+a_{1} z^{-1}+\cdots+a_{n} z^{-n}}=\frac{B(z)}{A(z)}
\end{aligned}
$$

The value of the parameter $n$ specifies the number of control steps. By dividing the numerator polynomial $B(z)$ and $A(z)$ in the denominator polynomial the $z$-transfer function of controlled system expressed as a polynomial $P(z)$ and $Q(z)$ is obtained:

$$
\begin{array}{r}
G_{\mathrm{s}}(z)=\frac{Y(z)}{U(z)}=\frac{\frac{Y(z)}{W(z)}}{\frac{U(z)}{W(z)}}=\frac{P(z)}{Q(z)} \\
=\frac{p_{1} z^{-1}+p_{2} z^{-2}+\cdots+p_{n} z^{-n}}{q_{0}+q_{1} z^{-1}+\cdots+q_{n} z^{-n}} .
\end{array}
$$

This discrete transfer function is converted to standard form $\left(q_{0}=1\right)$ and compared with the original 


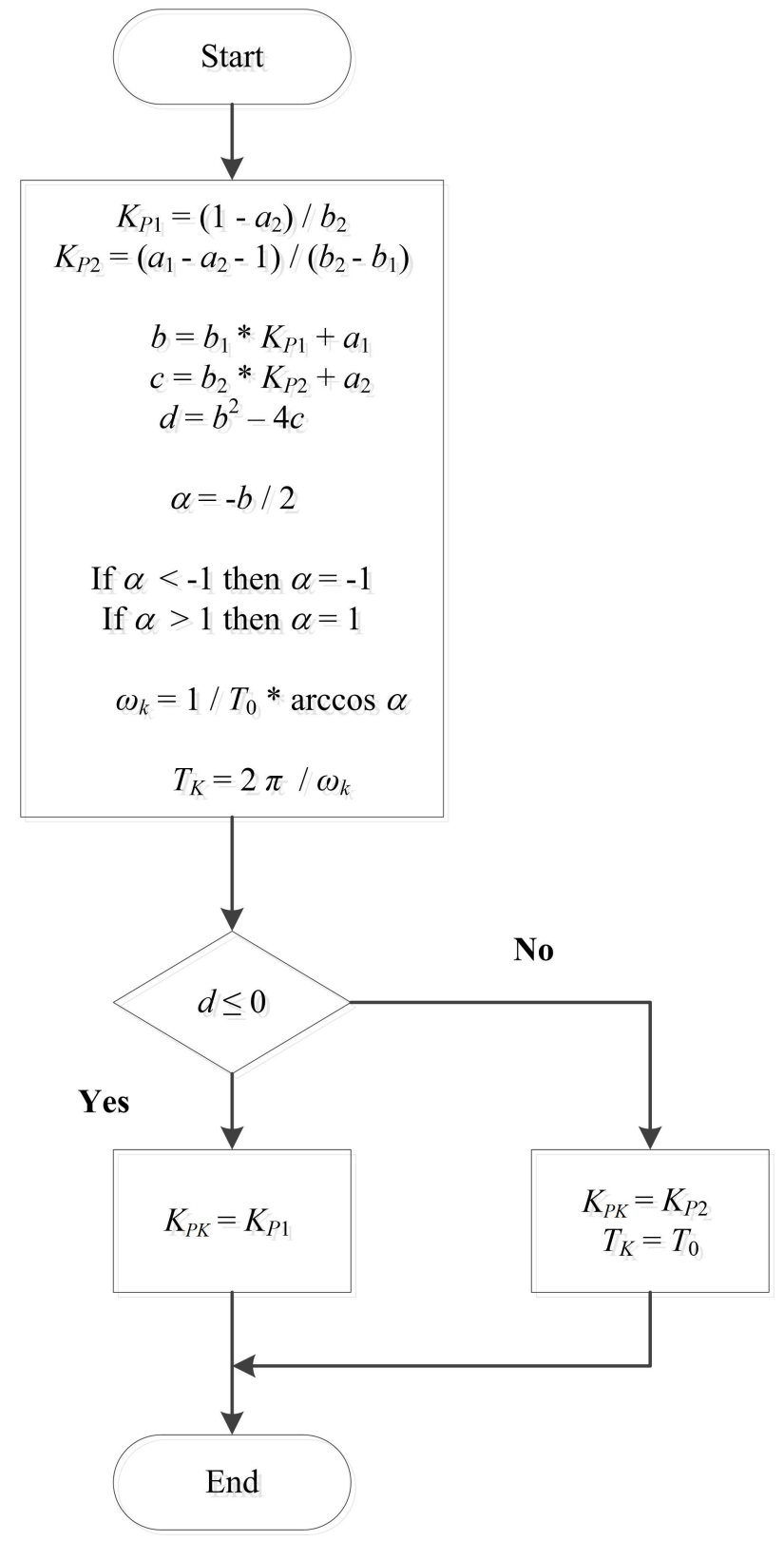

FiguRE 6. Algorithm for calculating critical parameters of PID controller [30].

polynomials in 21):

$$
\begin{aligned}
G_{\mathrm{S}}(z)=\frac{\frac{p_{1}}{q_{0}} z^{-1}+\frac{p_{2}}{q_{0}} z^{-2}+\cdots+\frac{p_{n}}{q_{0}} z^{-n}}{1+\frac{q_{1}}{q_{0}} z^{-1}+\cdots+\frac{q_{n}}{q_{0}} z^{-n}} \\
=\frac{b_{1} z^{-1}+b_{2} z^{-2}+\cdots+b_{n} z^{-n}}{1+a_{1} z^{-1}+\cdots+a_{n} z^{-n}} .
\end{aligned}
$$

By comparing the coefficients in powers of $z^{-1}$ in equation (16) we obtain the system of equations for calculating the coefficients of $q_{\mathrm{i}}$ and $p_{\mathrm{i}}$ on the basis of the coefficient $a_{\mathrm{i}}$ and $b_{\mathrm{i}}(i=1,2, \ldots, n)$ of the controlled system.

$$
\begin{gathered}
q_{\mathrm{i}}=a_{\mathrm{i}} q_{0}, \quad p_{\mathrm{i}}=b_{\mathrm{i}} q_{0}, \\
\sum_{\mathrm{i}=1}^{\mathrm{n}} p_{\mathrm{i}}=\sum_{\mathrm{i}=1}^{\mathrm{n}} b_{\mathrm{i}} q_{0}=1 .
\end{gathered}
$$

The parameter $q_{0}$ can be determined as follows:

$$
q_{0}=\frac{1}{\sum_{i=1}^{n} b_{i}}
$$

The transmission of the controller can be obtained by substituting values of the coefficients obtained by equations 17 and $(19)$ into the expression:

$$
\begin{aligned}
G_{\mathrm{R}}(z)= & \frac{1}{G_{\mathrm{S}}(z)} \frac{G_{\mathrm{W}}(z)}{1-G_{\mathrm{W}}(z)}=\frac{1}{\frac{P(z)}{Q(z)}} \frac{Q(z)}{1-P(z)} \\
& =\frac{q_{0}+q_{1} z^{-1}+\cdots+q_{n} z^{-n}}{1-p_{1} z^{-1}-p_{2} z^{-2}-\cdots-p_{n} z^{-n}}
\end{aligned}
$$

The control algorithm for system of the 2 nd order has the following form [17, 42]:

$$
\begin{aligned}
u(k)=q_{0} e(k)+ & q_{1} e(k-1)+q_{2} e(k-2)+ \\
& +\left(p_{1} u(k-1)+p_{2} u(k-2)\right)
\end{aligned}
$$

The derived algorithm can be applied to time-delaying processes and, similarly, it can be a derived equation of the controller for a higher order of the system.

In solving of the UCG control the Ziegler-Nichols method of the critical gain (i.e., open loop method according equation (7) that was presented was used, by means of which the parameters of continuous controllers were calculated. Then the continuous controller parameters were recalculated at a selected sampling period to discrete controller parameters in an incremental form. The Dead Beat method was not used for calculating the parameters of the controller because it was not considered suitable (see section 5.1. For calculating the parameters of the mathematical model of the controlled system, the ARX model was used, calculating by using the Least squares method in Matlab based on the data of the experimental identification.

\section{EXPERIMENTAL RESULTS AND DISCUSSIONS}

\subsection{Air FLOW STABILIZATION}

A basic variable in the control of the gasification process is the air flow that is supplied to the experimental gasifier. By changing the flow rate, we can influence the behaviour of chemical reactions during gasification.

For controlling the air flow in experimental gasification in the laboratory gasifier, a servo valve that was installed on the pipe to supply air from the pressure vessel was used. The air pressure in the pressure vessel was maintained between the minimum and maximum set point. An On-Off control method (i.e., Bang-Bang control) was used for the pressure stabilization [17, 29]. The servo valve behind the pressure vessel was connected to the control PLC that was operated via two digital signals. One signal was used for opening and the second for closing. The total time necessary to fully open or fully close the servo 


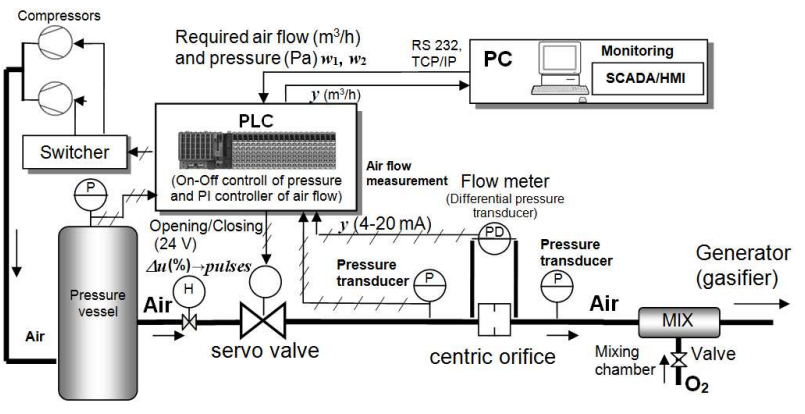

Figure 7. Control scheme of air flow stabilization by the servo valve.

valve is $30 \mathrm{~s}$. To ensure the full opening of the valve (i.e., opening to $100 \%$ ), the PLC must send 60 pulses with a duration of $500 \mathrm{~ms}$. A similar rule applies to the complete closure of the valve. They are discontinuous pulses, i.e., each pulse of the signal with a duration of $500 \mathrm{~ms}$ is followed by zero amplitude. The conversion of percentage to pulses is done using the following equation:

$$
u_{\text {pulses }}=u^{\%} \cdot 0.6,
$$

where $u^{\text {pulses }}$ is calculated as the change of the servo valve position in pulses, where one pulse is digital a signal with an amplitude of $24 \mathrm{VDC}$ and duration of $500 \mathrm{~ms}, u^{\%}$ is the change of the required servo valve position (\%).

Calculated pulses are rounded to the nearest integer. The created control system has programmed its own counter of pulses, because the electronics used in the servo valve does not provide any feedback information on the current servo valve position. The control system can also be configured for broadcasting of uninterrupted pulses.

Automatic flow control is based on the principle of stabilized measured airflow to the desired value. The air flow is calculated based on the measured pressure difference on the centric orifice and the air pressure before the orifice. The task of the control algorithm is consecutive at the specified time steps to close or open the servo valve so that the regulation deviation between the desired and measured flow is eliminated. This problem is solved by the equation of the discrete PI controller (3). The discrete controller calculates the percentage increase (or decrease) of the servo valve opening $\Delta u$ on the basis of deviation $e$. Control deviation $e$ is calculated as the difference between the desired value $w$ (i.e., set point) and the measured flow $y$ of the air. In Figure 7 the scheme for stabilizing the air flow through the servo valve is provided.

For the calculation of unknown controller parameters $q_{0}, q_{1}$ an experimental identification of the controlled system was performed. Experimental identification is based on the principle of a step excitation of the regulated system, follow-up and record of the responses of the controlled variable - air flow (see Figure 8).

For calculation of the model parameters, Matlab func-

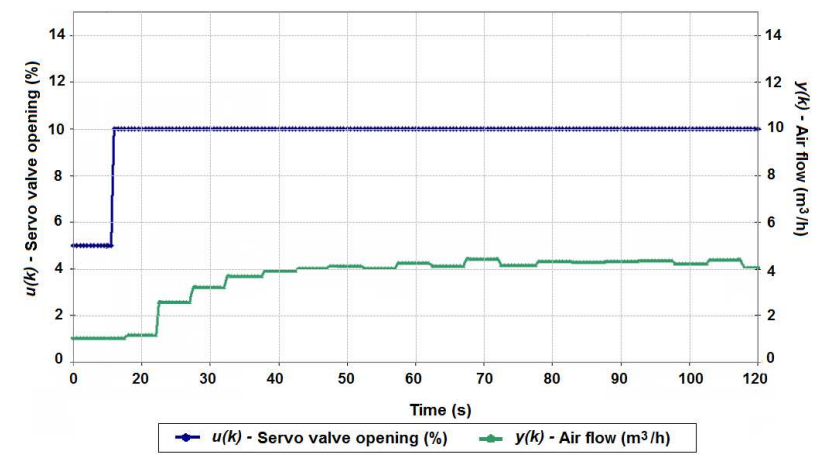

Figure 8. System identification with $5 \%$ servo valve opening.

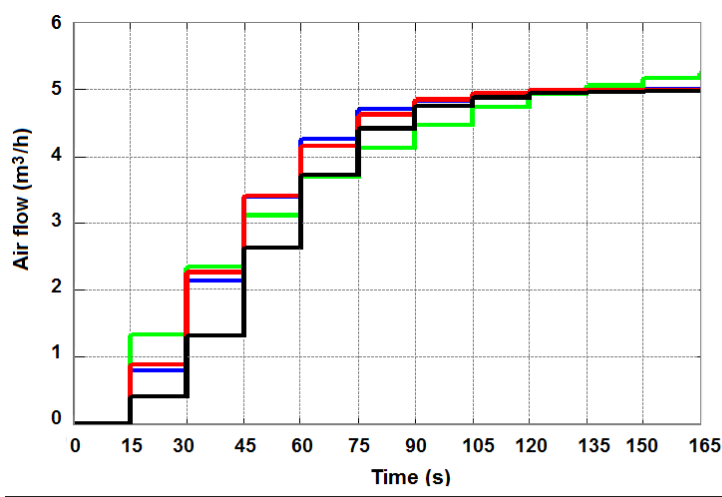

The $1^{\text {st }}$ order system: $J=1.3045 \longrightarrow$ The $2^{\text {nd }}$ order system: $J=0.0398$ $\longrightarrow$ The $3^{\text {rd }}$ order system: $J=1.7498 \longrightarrow$ Measured data

Figure 9. Comparison of measured data with the models.

tions of parametric identification were implemented 43 . The functions of the System Identification Toolbox were applied to calculate the parameters of the ARX model. The result is a model of the second order in the form of a discrete $z$-transfer function (23). This model was converted to the differential equation in the form (24). Parameters $a_{1}, a_{2}, b_{1}, b_{2}$ of the second order differential equation are the results achieved from identification 43].

Overall, models of the 1st, 2nd and 3rd order were calculated and then compared with the measured data. Models in the form of the $z$-transfer function were transferred into differential equations $24-26)$ :

$$
\begin{aligned}
& G_{\mathrm{S}}\left(z^{-1}\right)= \frac{b_{1} z^{-1}+b_{2} z^{-2}}{1+} a_{1} z^{-1}+a_{2} z^{-2} \\
&=\frac{2.46 z^{-1}+2.453 z^{-2}}{1-1.118 z^{-1}+0.367 z^{-2}}, \\
& y_{\mathrm{M}}(k)=-(-0.7584 y(k-1)) \\
&+(5.324 u(k-1)) \\
& y_{\mathrm{M}}(k)=-(-1.118 y(k-1)+0.367 y(k-2)) \\
& \quad+(2.46 u(k-1)+2.453 u(k-2)), \\
& y_{\mathrm{M}}(k)=-(-1.26 y(k-1)+0.6419 y(k-2)
\end{aligned}
$$




$$
\begin{aligned}
& \quad+0.1392 y(k-3)) \\
& +(1.619 u(k-1)+1.619 u(k-2) \\
& \quad+1.619 u(k-3)) .
\end{aligned}
$$

For verification of the models, graphical comparison of the measured and model data was used, it also served as a review of equality of the stabilized values and a quantitative statement by quadratic criterion (27) 43.

$$
J=\int_{0}^{\tau}\left[y(t)-y_{\mathrm{M}}(t)\right]^{2} d t=\sum_{k=1}^{N}\left(y(k)-y_{\mathrm{M}}(k)\right)^{2} \Delta \tau,
$$

where $y(k)$ is an output from the real system, $y_{\mathrm{M}}(k)$ is an output from model, $k$ is the time step, $t$ is the time, $N$ is the number of the measured samples 43 .

In regard to lowest value of criterion 27) at the 2nd order of the model, this model was used for the calculation of the controller's parameters 43. The result of comparison is depicted in Figure 9

For the calculation of the parameters of the discrete PI controller (i.e., $q_{0}, q_{1}$ ) for a specified sampling period, the modified Ziegler-Nichols method was used (see Figure 6). This method enables us to estimate parameters of the PI or PID controller directly from the parameters of the discrete model $(24)-(26)$. Equation 28 represents the discrete PI controller in an incremental form:

$$
\begin{aligned}
\Delta u(k)= & u(k)-u(k-1) \\
= & q_{0} e(k)+q_{1} e(k-1) \\
& =0.116123 e(k)-0.086580 e(k-1)
\end{aligned}
$$

where $u$ is the control variable, $e$ is the control error, $k$ is an index of the control period, $w$ is the desired value, $y$ is the controlled variable, $K_{\mathrm{P}}$ is the proportional constant, $T_{\mathrm{I}}$ is an integration constant, $T_{0}$ is the sampling period [43].

With consideration of the different pressure conditions, it is necessary to use other controllers of parameters, because the controlled system changes its parameters, several controllers for different pressure were calculated. A programmed algorithm of the discrete PI controller always chooses the parameters of $q_{0}, q_{1}$ which correspond to the proposed controller in the selected overpressure.

Similarly, the control parameters for the various air flows are changed. From previously described facts, results show that the system identification must be completed on a several air flow levels and different pressures adjusted on the reducing valves. The opening of servo valve with a smaller inlet pressure has resulted in a lower airflow rate and the same great opening, but with a higher overpressure, will result in a higher airflow rate.

The behaviour of the stabilization of the air flow for different pressure conditions during experimental gasification is shown in Figure 10

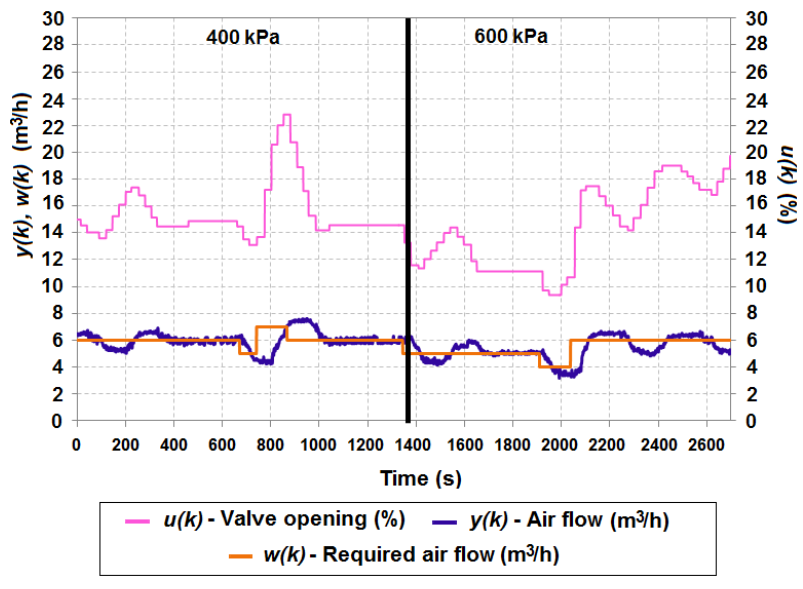

Figure 10. Behaviour of air flow stabilization during gasification at various overpressures.

A Deat Beat controller 29 calculated according to equations (17)-21 was not used during the UCG experiments, because in the first step of regulation it caused a major change of the control variable $u$ (i.e., in some cases, the opening of the servo valve was up to $100 \%$ ) and that is an undesired state. An excessive opening of the servo valve in the first step of the control causes the venting of the air from the pressure vessel and a significant pressure. In the next step, the entirely closed and even slightly opened valve causes large oscillations of the system. The classical Dead Beat controller needs, by a small number of steps, to stabilize the system, which causes that control variable to jump from one extreme to the other. The result of the practical verification of the Dead Beat controller is shown in Figure 11. The figure shows a short stretch of the control with the discrete PI controller, followed by the control with the Dead Beat controller. The graphical comparison shows that the Dead Beat controller is not suitable for stabilizing the flow of air that comes from the pressure vessel. An alternative for the application of the Dead Beat controller could be the use of high pressure blower. This type of controller was also successfully implemented in the control of time delayed system [44]:

$$
\begin{aligned}
& \begin{array}{c}
\Delta u(k)=q_{0} e(k)+q_{1} e(k-1)+q_{2} e(k-2) \\
+\left(p_{1} u(k-1)+p_{2} u(k-2)\right) \\
=0.2035 e(k)-0.2275 e(k-1)+0.0746 e(k-2) \\
\quad+(0.5 u(k-1)+0.5 u(k-2)) .
\end{array}
\end{aligned}
$$

\subsection{Temperature Stabilization}

The aim was to inject air into the ex-situ reactor (i.e., syngas generator) with a flow that would ensure that the content of the heating components would be the highest. This aim can be achieved only at higher temperatures above $1000^{\circ} \mathrm{C}$. With increasing temperature, the production of $\mathrm{CO}$ increases (see Figure 12 and this component remains dominant. 


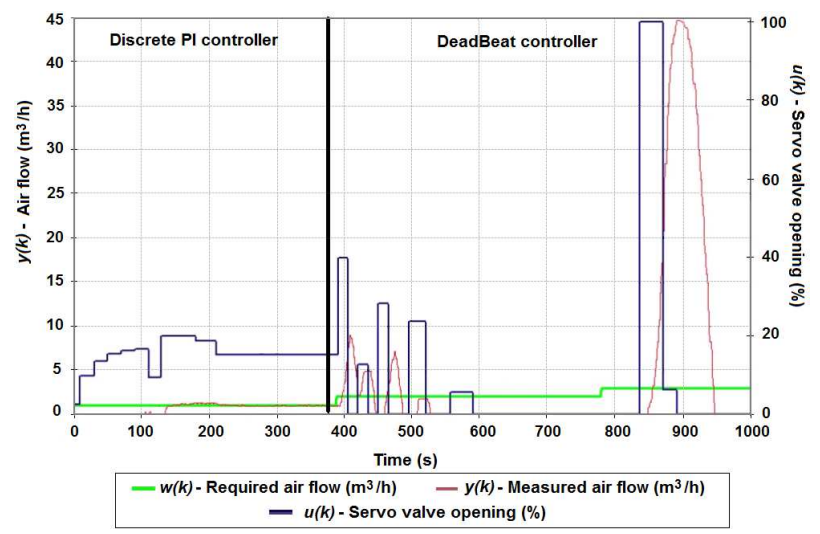

Figure 11. Control with discrete PI and Dead Beat controller.

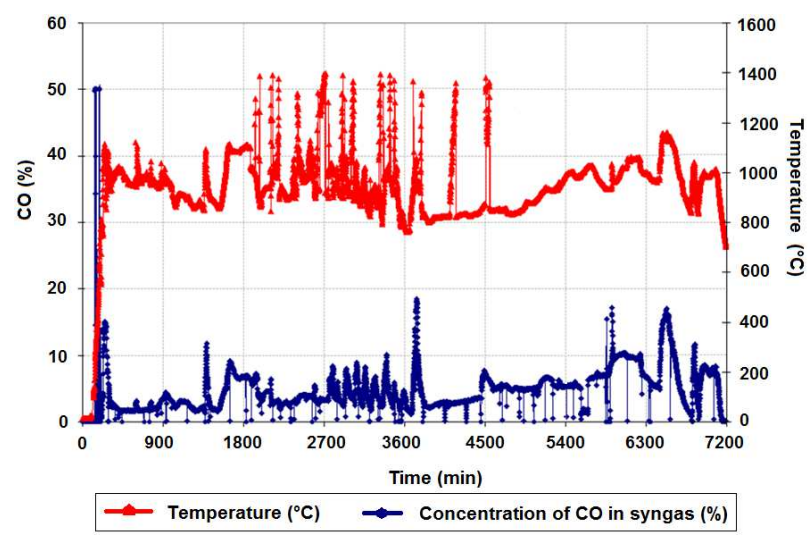

FiguRE 12. Increase of CO concentration in syngas when temperature increases.

Similarly, it increases the ratio of $\mathrm{CO} /\left(\mathrm{CO}+\mathrm{CO}_{2}\right)$, which is an important indicator during gasification (see Figure 13) [45. However, the higher temperature should be maintained in the long term so that the syngas is produced as long as possible (see section 1.2. For this reason, it is necessary to implement an algorithm for stabilizing the temperature to the desired value.

Temperature stabilization in the experimental gasifier is based on the same principle as the stabilization of the air flow. The controlled variable $y$ is the current highest temperature of coal, in the channel or by an operational personnel selected temperature (i.e., thermocouple by number). The feedback control algorithm includes an auxiliary algorithm that identifies the maximum (i.e., the highest) temperature $T_{\max }$ from all measured temperatures. Control variable $u$ is the percentage opening of the servo valve, which at a given pressure corresponds to the air flow.

The discrete PI controller calculates the percentage increment of the servo valve opening or closing. The desired percentage change is then converted in the PLC to a number of pulses (see Figure 14). The Discrete PI controller changes the supplied air flow, so that the selected temperature is stabilized. If it is necessary

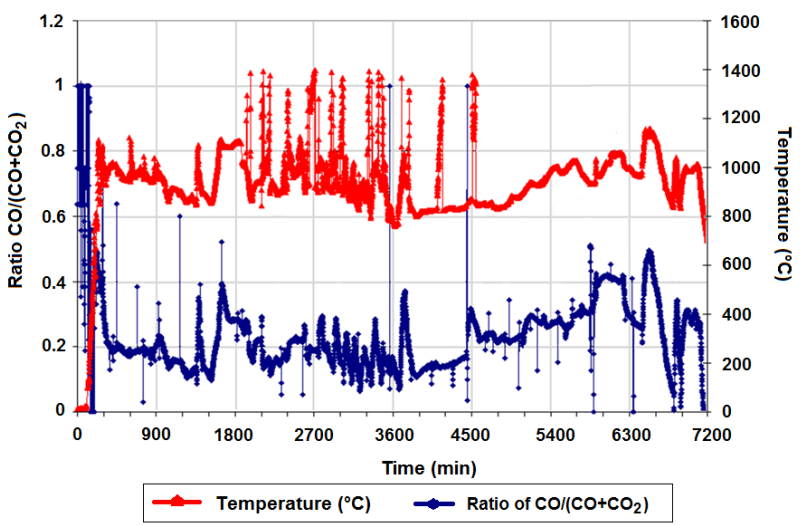

Figure 13. Example of increasing ratio $\mathrm{CO} / \mathrm{CO}+\mathrm{CO}_{2}$ when temperature increases during gasification.

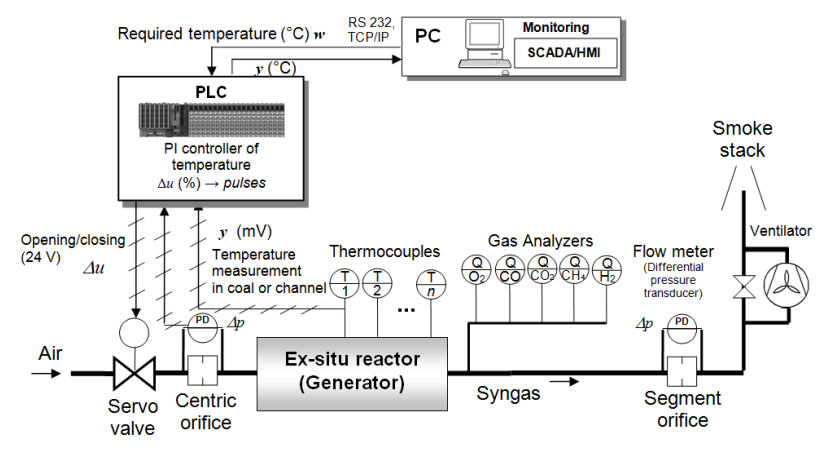

FiguRE 14. Scheme of PI controller connections for the temperature stabilization.

to increase the temperature, the controller increases the air flow. If the measured temperature is above the set point, the controller reduces the airflow. The calculated model of the controlled system in the form of a discrete transfer function is expressed by (30). A model of the controller is also expressed in the form of a discrete transfer (31) and by the algorithm in the form of a differential equation 32:

$$
G_{\mathrm{S}}\left(z^{-1}\right)=\frac{199.1 z^{-1}+199.1 z^{-2}}{1-0.437 z^{-1}-0.05025 z^{-2}} .
$$

A discrete transfer of the controller has the form

$$
G_{\mathrm{R}}(z)=\frac{q_{0}+q_{1} z^{-1}}{1-z^{-1}}=\frac{0.00027-0.00004115 z^{-1}}{1-z^{-1}} .
$$

An algorithm of controller has the following form:

$$
\begin{gathered}
\Delta u(k)=u(k)-u(k-1)=q_{0} e(k)+q_{1} e(k-1) \\
=0.00027 e(k)+(-0.00004115 e(k-1))
\end{gathered}
$$

where $\Delta u(k)$ is an increase of control variable $u, k$ is the time step, $e(k)$ is the regulation error $(e(k)=w(k)-y(k)), y(k)$ is the measured temperature (i.e., controlled variable) $\left({ }^{\circ} \mathrm{C}\right), w(k)$ is the desired value $\left({ }^{\circ} \mathrm{C}\right)$.

In Figures 15 and 16 temperature stabilization behaviours with the discrete PI controller for different 


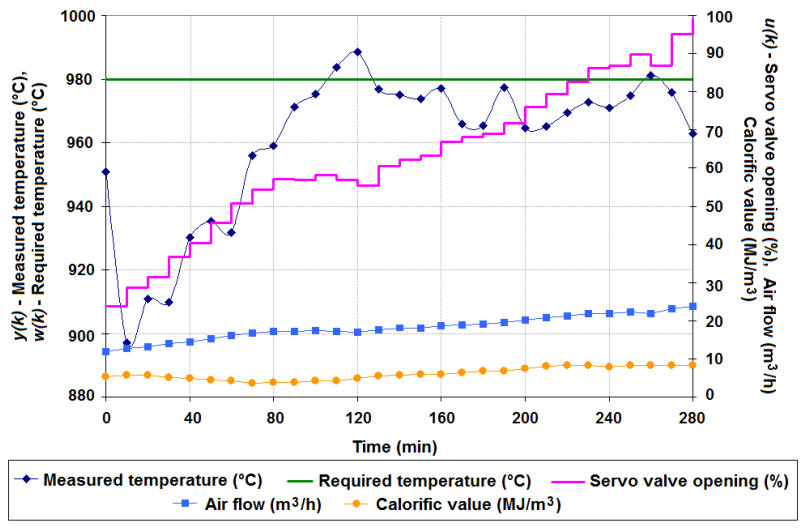

Figure 15. Temperature stabilization on $980^{\circ} \mathrm{C}$.

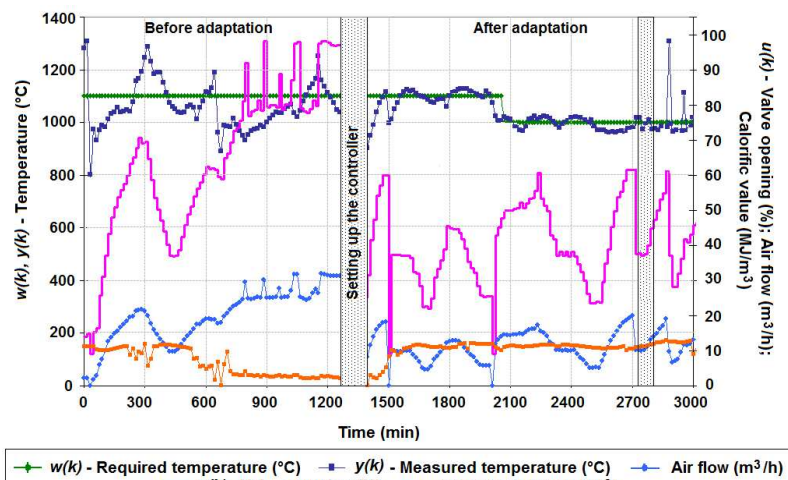

$\rightarrow w(k)$ - Required temperature $\left({ }^{\circ} \mathrm{C}\right) \rightarrow y(k)$ - Measured temperature $\left({ }^{\circ} \mathrm{C}\right) \rightarrow-$ Air flow $\left(\mathrm{m}^{3} / \mathrm{h}\right)$

Figure 16. Adaptation of the controller for the regulated system.

set points are graphically illustrated. The graphs also show how the calorific value of syngas varied during the temperature stabilization. The controller's parameters need to be calculated continuously as the controlled system is gradually changing. In Figure 16 the time behaviour of the temperature stabilization during the gasification process is shown. In the second half of the graph we can see the behaviour after new identification and calculation of new controller parameters. The controller was adapted on the current state of the process and the next steps sufficiently stabilized the temperature. Because temperature cannot be measured directly inside the cavity, a proxy is needed that can provide a reliable indication of the temperature [46]:

- Proxy by measured carbon isotopes [46].

- Proxy by measured concentration of $\mathrm{CO}, \mathrm{CO}_{2}$ and its ratio (e.g., $\left.\mathrm{CO} /\left(\mathrm{CO}+\mathrm{CO}_{2}\right)\right)$ [45].

- Proxy by measured emanation of radon from underground to surface [47].

- Proxy by mathematical model based on theory of heat conduction [48, 49].

Monitoring of temperature by measuring of carbon isotopes - The results show that the isotope value increases with each temperature step, until it stabilizes at a certain temperature [46. This trend shows that fractionation is occurring in the low temperature range, where relatively light components are released. Once the value stabilizes in the high temperature range, fractionation no longer takes place and the isotope signature represents the value for bulk coal [46]. In general, the temperature at which the value is stabilized increases with increasing rank. Isotopes are variants of a particular chemical element which differ in neutron number, although all isotopes of a given element have the same number of protons in each atom. Delta value would appear to be a good proxy, but only if the stabilization temperature would have been higher than the operational temperature for UCG [46].

Monitoring by Radon measurement - This technique can be used for the detection of the length and moving velocity of the gasification working face. In the experiment, the length and moving velocity of the gasification working face are detected with the help of the radon measuring technique. Radon $\left({ }_{222} \mathrm{Rn}\right)$ is the only gaseous derivative in the disintegration of the natural radioelement, which possesses the unique feature of emitting vertically from the underground to ground surface [50]. The moving of radon is closely linked to temperature. When the temperature rises, the emanation coefficient of radon increases remarkably [47]. Therefore, measuring the radon concentration on the surface of the earth can reflected the temperature beneath. The Rn emanation factor increases dramatically when temperature is greater than $700{ }^{\circ} \mathrm{C}$. Radon solubility decreases as the temperature increases [51. This method can be used for detection of the UCG burn-front and estimation of its migration speed.

\subsection{Stabilization of Oxygen Concentration In The Syngas}

During gasification, the task is to maintain the concentration of $\mathrm{O}_{2}$ in the gas at the lowest possible value. Then, a higher concentration of CO is achieved and the resulting calorific value of gas is higher. Figure 17 shows the behaviour of the measured concentrations of $\mathrm{O}_{2}$ and corresponding calorific value calculated from the gas composition. Oxygen is measured by the analyser for oxygen with a range of $0-21 \%$. High concentrations of oxygen $(10-21 \%)$ in the produced gas, mean that a large volume of oxidant is blown, causing the cooling of coa, which decreases the calorific value. There can also be a high concentration of $\mathrm{O}_{2}$ in the gas caused by the fact that there is insufficient carbon oxidation during combustion in the oxidation zone, and consequently there are also low temperatures in oxidation and the reduction zone and less CO is produced.

High concentration of $\mathrm{O}_{2}$ in the gas can also mean, that through gaps, porosity, rifts or leakages in the pipe system, air is sucked into the reactor, which then enriches the produced gas with its oxygen. For stabilization of the $\mathrm{O}_{2}$ concentration in the produced gas, an alternate feedback controller was programmed. 


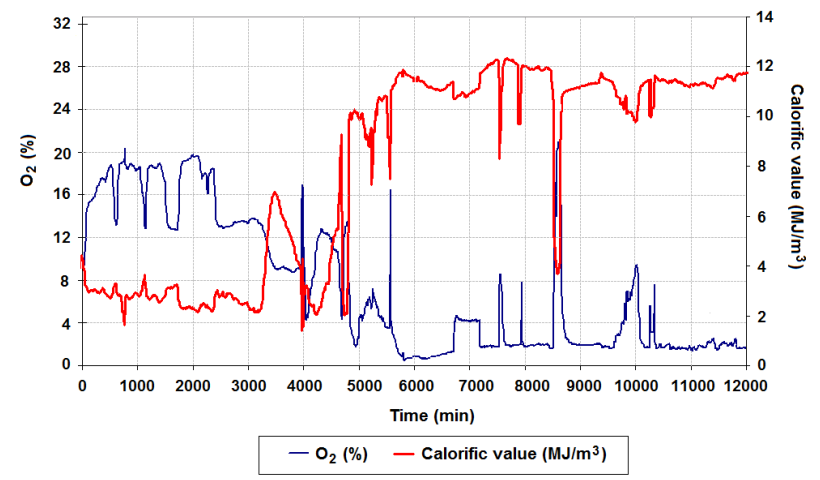

Figure 17. Effect of $\mathrm{O}_{2}$ concentration on the calorific value.

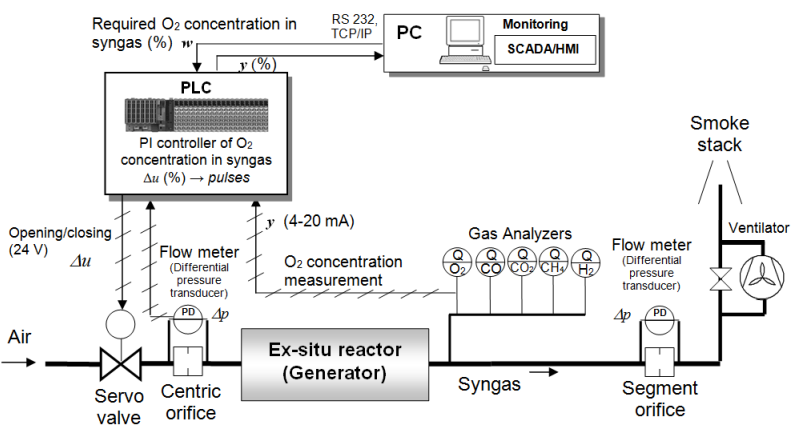

Figure 18. Connection scheme of stabilization concentration of $\mathrm{O}_{2}$ by airflow.

It is a discrete form of a continuous PI controller as in the case of the stabilization of the air flow and temperature (see section 4 ).

The basis of the control algorithm is the controller equation (3), which calculates a new addition of the control variable in each step of the control algorithm. The control variable $u$ is the percentage change in the position of the servo valve or exhaust fan motor power frequency. The change in the opening of the servo valve can change the air flow and affect the behaviour of chemical reactions that take place during gasification. In the second case, change of the fan power (i.e by change of power frequency) can change the amount of the intake air, under-pressure and the flow of produced gas. An equation of the controller (3) calculates the manipulated variable, which is in the range of $0-1$ (i.e., $0-100 \%$ of valve opening). Regarding the control of the exhaust fan power, the control variable is also in the range of $0-1$ (i.e $0-100 \%$ of the exhaust fan motor power). This range corresponds to the frequency range of $0-50 \mathrm{~Hz}$, which the PLC sends to the frequency inverter (see Figure 19.

In the first case, the control algorithm calculates in each step the control variable percentage to the number of pulses opening or closing the servo valve according to equation (3). The connection diagram of the feedback controller for the stabilization of $\mathrm{O}_{2}$ concentration by air flow is shown in Figure 18. If it is necessary to increase the concentration of $\mathrm{O}_{2}$, the controller

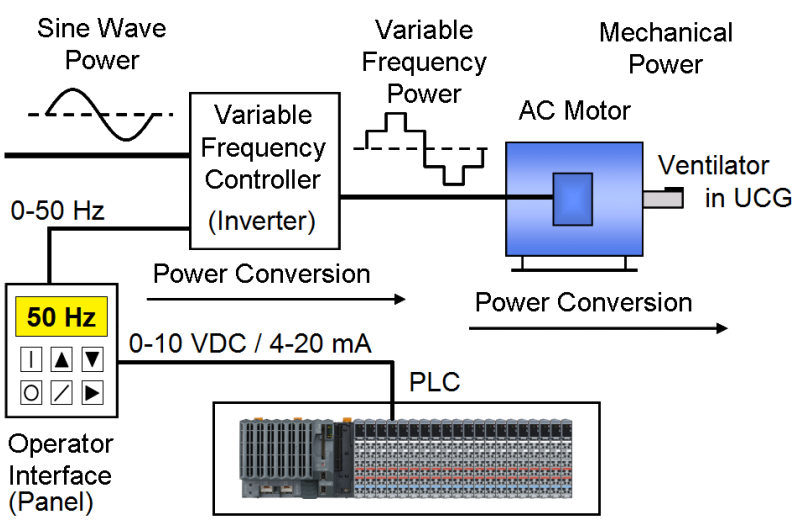

FiguRE 19. Variable frequency drive of exhaust fan.

increases the air flow and vice versa. Similarly, a second stabilizing loop is created. The $\mathrm{O}_{2}$ concentration in the produced gas in this case is stabilized by the power of an exhaust fan. The control variable is the power frequency of the motor calculated by control system according to equation (33) and sent as an analog voltage signal $(0-10 \mathrm{VDC})$ to the frequency inverter (see Figure 20. We have used a variable-frequency drive (VFD) which is a type of an adjustable-speed drive used in electro-mechanical drive systems to control the AC motor speed and torque by varying motor input frequencies and voltage [52]. A three-phase AC motor for exhaust of syngas was used. The frequency power can be setup directly on the inverter panel (i.e., operator interface) or via a controller (i.e., control task) actioned via the PLC. In the case of the need to increase the $\mathrm{O}_{2}$ concentration, the controller increases the frequency. If the measured concentration of $\mathrm{O}_{2}$ is above the set point, the controller reduces the power frequency of the inverter. Globally, there is a practice of using a technique for the control of combustion, which uses only the exhaust fan at the end of the outlet hole during the gasification process 18 .

$$
u^{\mathrm{V}}=u^{\mathrm{Hz}} \cdot 0.2
$$

where $u^{\mathrm{V}}$ is the value of the analogue voltage signal $(\mathrm{V}), u^{\mathrm{Hz}}$ is the desired power frequency $(\mathrm{Hz})$.

For proposal of the controller, it was necessary to perform an experimental identification of the controlled system $(u$ is the servo valve opening or motor power frequency of the ventilator, $y$ is the concentration of $\mathrm{O}_{2}$ in syngas). The record of measured values was used for the identification.

A model of the regulated system is described by the following $z$-transfer function:

$$
G_{\mathrm{S}}\left(z^{-1}\right)=\frac{6.509 z^{-1}+6.509 z^{-2}}{1-0.7325 z^{-1}+0.1985 z^{-2}} .
$$

Using the Ziegler-Nichols method and algorithm shown in Figure 6 the parameters of continuous PI controllers, which are converted to discrete form, were calculated. Model of the regulated system "exhaust fan 


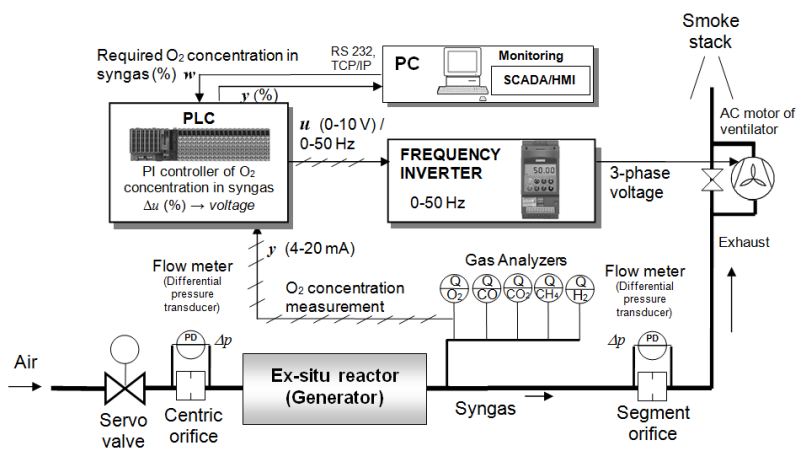

Figure 20. Connection scheme of $\mathrm{O}_{2}$ stabilization by exhaust fan power.

power frequency $-\mathrm{O}_{2}$ concentration" is described by $z$-transfer:

$$
G_{\mathrm{S}}\left(z^{-1}\right)=\frac{3.8095 z^{-1}+3.8095 z^{-2}}{1-0.7218 z^{-1}+0.0804 z^{-2}} .
$$

The model of the controller for stabilization of $\mathrm{O}_{2}$ concentrations by air flow is as follows:

$$
\begin{aligned}
\Delta u(k)= & q_{0} e(k)+q_{1} e(k-1) \\
& =0.021 e(k)+(-0.0123 e(k-1)) .
\end{aligned}
$$

The model of the controller for stabilization of the $\mathrm{O}_{2}$ concentrations by frequency inverter of the exhaust fan is in the form:

$$
\begin{aligned}
& \Delta u(k)=q_{0} e(k)+q_{1} e(k-1) \\
& \quad=0.1086241 e(k)+(-0.073843 e(k-1)),
\end{aligned}
$$

where $\Delta u(k)$ is an increment of the control variable $u$, $k$ is the time step, $e(k)$ is the regulation error (where $e(k)=w(k)-y(k)), y(k)$ is the concentration of $\mathrm{O}_{2}$ i.e., controlled variable (\%), $w(k)$ is the desired value $(\%)$.

In Figure 21 and Figure 22, there is a graphic presentation of the testing of the stabilization of the $\mathrm{O}_{2}$ concentrations by the air flow during gasification. The sampling period was set to $T_{0}=10 \mathrm{~min}$ and it set the point $w(k)$ for $\mathrm{O}_{2}$ stabilization as it gradually changed. For the measuring of the concentrations of $\mathrm{O}_{2}$, the last set point was reached after $210 \mathrm{~min}$. Then the sampling rate was increased to $T_{0}=15 \mathrm{~min}$.

In terms of the quality of the gasification process, the stabilization of the concentration of $\mathrm{O}_{2}$ at $1 \%$ reached the maximum calorific value of $5 \mathrm{MJ} / \mathrm{m}^{3}$ (see Figure 22). A test of the controller was performed during the trial on an experimental coal gasifier.

In the second test (see Figure 23), an $\mathrm{O}_{2}$ concentration of $5 \%$ and sampling period $T_{0}=5 \mathrm{~min}$ was desired. The measured concentration reached the desired value after $35 \mathrm{~min}$. In terms of the quality of the gasification process, after stabilization of the $\mathrm{O}_{2}$ concentration at $5 \%$, it reached the maximum calorific value of $0.35 \mathrm{MJ} / \mathrm{m}^{3}$ on average (see Figure 24). The test took place during gasification on the laboratory gasifier.

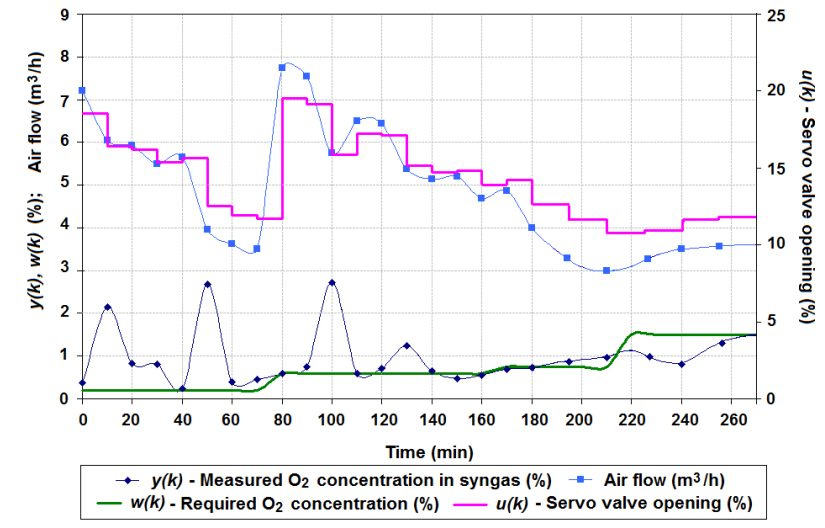

FiguRE 21. Stabilization of $\mathrm{O}_{2}$ concentration on a various desired values.

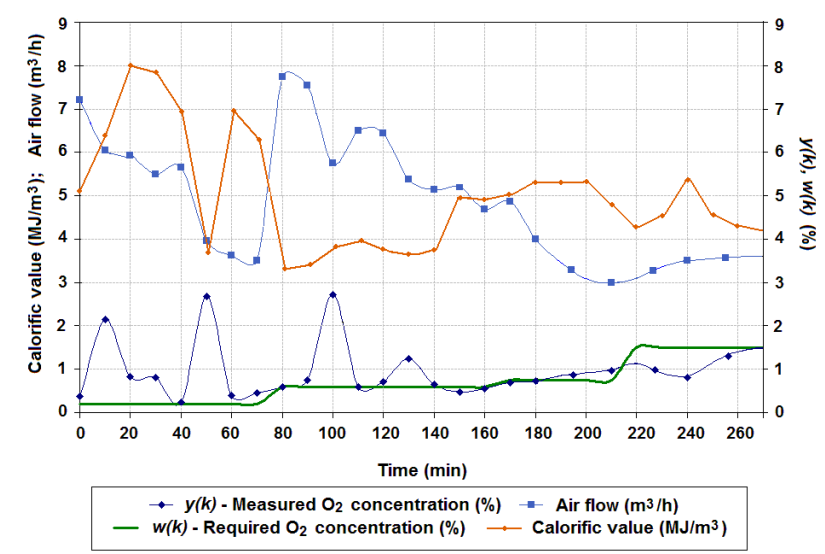

Figure 22. Calorific value and the $\mathrm{O}_{2}$ concentration in stabilizing.

The above results indicate that the stabilization of the $\mathrm{O}_{2}$ concentration at lower values allows a higher calorific value of the produced gas. The ideal situation occurs when the concentration of $\mathrm{O}_{2}$ in the syngas is stabilized at $0 \%$.

Similarly, the controller for the stabilization of the concentration of $\mathrm{O}_{2}$ with a fan was tried. In Figure 25 the practical verification of the controller is shown. The figure shows how change occurs in the value of the frequency inverter and how the $\mathrm{O}_{2}$ concentration responds. The controller reached the set point after 40 minutes and maintained it until a fault occurred. The disturbances arose as a result of changes to the air intake, because this controller usually starts along with the controller for the temperature stabilization or extremal controller. The controller was verified during the experiment with the gasification in the laboratory gasifier. We can see that a new setting of the controller (i.e., adaptation) increases the quality of the $\mathrm{O}_{2}$ stabilization (see Figure 25].

In case that the monitoring system indicates a high concentration of poisonous and explosive gases on the surface caused by gas leaks from underground, we propose to change the UCG control from pressurized to under-pressurized. In under-pressure control, the 


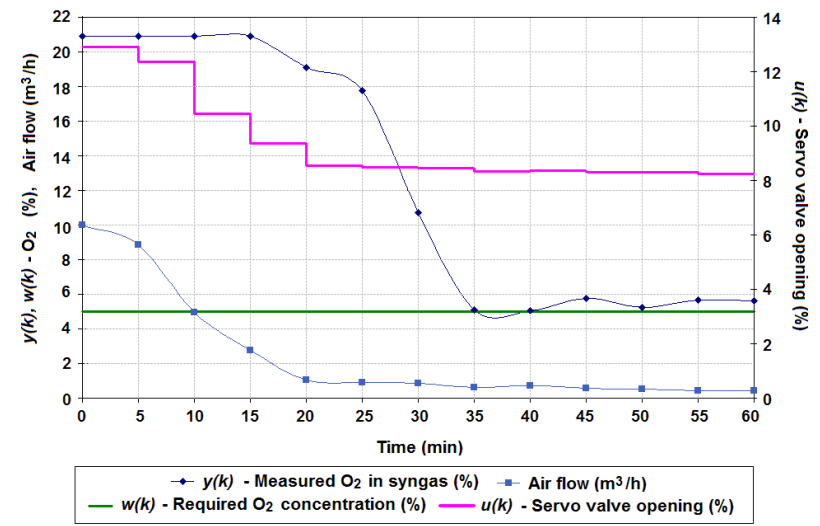

Figure 23. Stabilization of $\mathrm{O}_{2}$ concentration to $5 \%$.

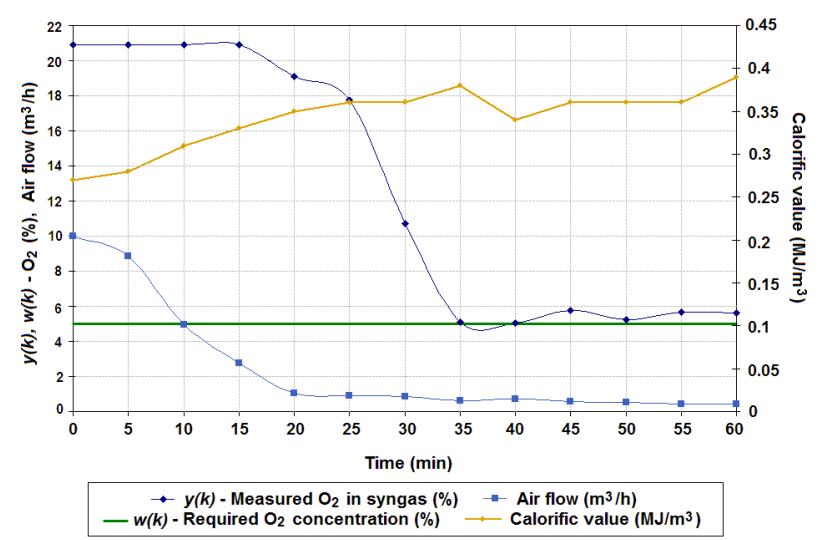

Figure 24. Calorific value during stabilization of $\mathrm{O}_{2}$ concentration.

gasification is controlled only with sucked air and injection of oxidizer is closed. The under-pressure can be adjusted by the power of suction fan. The control of the UCG with under-pressure prevents gas leaks from underground to the surface but the concentration of oxygen in syngas should be controlled.

\section{Conclunsions}

The construction of an underground industrial gasification system for a real coal seam requires not only the knowledge of geology and of the process itself, but also an investment needed to build systems for measurement and automatic control of the gasification process. In this paper, the problem of a gas control in the UCG was solved. The issue in question is the stabilization level and supportive adaptation level. Knowledge gained from the manual process control tests were used to design controllers for stabilization levels. The stabilization level was built on the basis of a discrete proportional-summing controller. The outcome is a control system for the stabilization of oxidant to the gasifier, control system for the stabilization of the temperature in the gasifier and control system for the stabilization of the oxygen concentration in the produced gas.

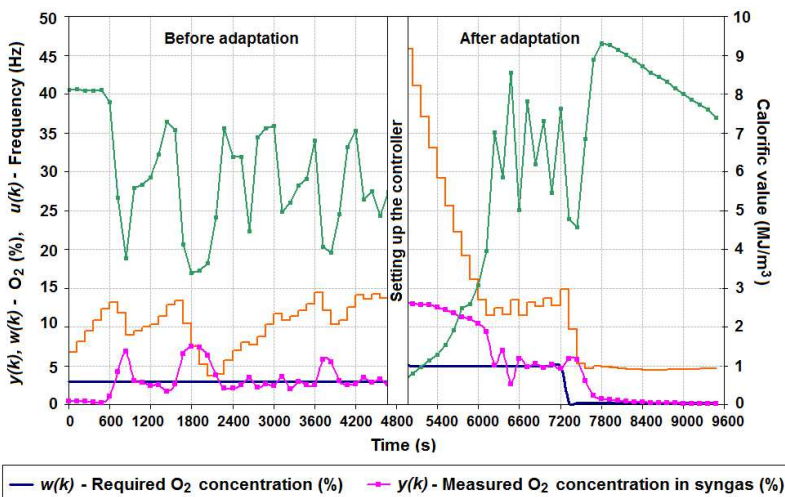

$-u(k)$ - Inverter frequency $(\mathrm{Hz}) \rightarrow$ Calorific value $\left(\mathrm{MJ} / \mathrm{m}^{3}\right)$
$-u(k)$ - Measured $\mathrm{O}_{2}$ concentrato

Figure 25. Stabilization of $\mathrm{O}_{2}$ by exhaust fan power frequency.

The main objective in the verification of the control algorithms was the maximization of the produced syngas calorific value. Despite the complexity of the control system, an implemented system could be improved in the future.

The benefit would be an improvement of the system for centralized control of the controllers and improvement of the system for visualization and evaluation of specific measured values. In experimental gasification on a lab scale, we have used Lignite from Slovak mines. We suggest building automated control systems for a gas control with the following recommendations:

- We propose to build a stabilization level based on the discrete feedback controllers (PI/PID). We propose the use of methods of discrete parametric process identification and a model-based method of the controller design.

- We propose to support the stabilization level with the adaptation of controllers due to recognized uncertainties. We propose to use the principle of Self-Tuning Controllers (STC). By stabilizing levels it will stabilize inputs into the process of the UCG (i.e., pressure, flow oxidants) as well as outputs (i.e., underground temperature, concentration of $\mathrm{O}_{2}$ in the syngas).

- In the case that the UCG is controlled by the pressure of the injected gas, a consistent monitoring of gas leaks from underground is essential.

- In the case that there is any reason to inject an oxidant with pressure into the cavity, we propose to extend the control system to monitor a leakage of syngas.

- If the monitoring system detects the presence of syngas in vulnerable areas (although far from the vulnerable area), we recommend to switch from a pressurized system to under-pressurized controlled by the fan power. In this case, the concentration of $\mathrm{O}_{2}$ in the syngas must be checked.

- If there is no serious reason to transport the oxidizer by overpressure regime, then we recommend the 
control system to be built on the principle of an under-pressure control.

- We suggest stabilizing the temperature at $1000{ }^{\circ} \mathrm{C}$ in the oxidizing zone and keeping the oxygen concentration close to zero for the best performance of the UCG reactor.

Although the automated control system for the gas control was tested only in laboratory conditions, it can be used with some modifications in real UCG operational environments.

\section{ACKNOWLEDGEMENTS}

This work was supported by the project COGAR RFCRCT-2013-00002, by the Slovak Research and Development Agency under contract APVV-14-0892 and grants VEGA 1/0273/17 and VEGA 1/0529/15 from the Slovak Grant Agency for Science.

\section{REFERENCES}

[1] A. W. Bhutto, A. A. Bazmi, G. Zahedi. Underground coal gasification: From fundamentals to applications. Progress in Energy and Combustion Science 39(1):189-214, 2013. DOI:10.1016/j.pecs.2012.09.004

[2] A. Khadse, M. Qayyumi, S. Mahajani, P. Aghalayam. Underground coal gasification: A new clean coal utilization technique for india. Energy 39(11):2061-2071, 2007. DOI:10.1016/j.energy.2007.04.012.

[3] R. P. Verma, R. Mandal, S. K. Chaulya, et al. Contamination of groundwater due to underground coal gasification. International Journal of Water Resources and Environmental Engineering, academicJournal 6(12):303311, 2014. http://www . academicjournals.org/ article/article1420795093_Verma\%20et\%20al..pdf DOI:10.5897/IJWREE2014.0520

[4] C. Higman, M. van der Burgt. Gasification, Second Edition. Gulf Professional Publishing, Elsevier; 2nd edition, Oxford, UK, 2008.

[5] Anon. Underground coal gasification program. Technical report, Booz, Allen \& Hamilton, Inc., Report ERDA 77-51/4 on Contract No. EX-76-C-01-2343, US Energy Research and Development Administration, 1977.

[6] T. Ishikawa, T. Nagaoki. Recent Carbon Technology. JEC Press Inc., Cleveland, Ohio. USA, 1983.

[7] A. A. Uppal, A. I. Bhatti, E. Aamir, et al. Control oriented modeling and optimization of one dimensional packed bed model of underground coal gasification. Journal of Process Control 24:269-277, 2014. DOI:10.1016/j.jprocont.2013.12.001

[8] A. Arshad, A. I. Bhatti, R. Samar, et al. Model development of UCG and calorific value maintenance via Sliding mode control. In 2012 International Conference on Emerging Technologies, pp. 1-6. 2012. DOI:10.1109/ICET.2012.6375477

[9] Q. Wei, D. Liu. Adaptive dynamic programming for optimal tracking control of unknown nonlinear systems with application to coal gasification. Transactions on Automation Science and Engineering, IEEE

11(4):1020-1036, 2014. DOI:10.1109/TASE.2013.2284545
[10] P. Ji, X. Gao, D. Huang, Y. Yang. Prediction of syngas compositions in shell coal gasification process via dynamic soft-sensing method. In Proceeding of 10th IEEE International Conference on Control and Automation (ICCA), pp. 244-249. 2013. DOI:10.1109/ICCA.2013.6565140

[11] M. Laciak, J. Kačur, K. Kostúr. The verification of thermodynamic model for UCG process. In ICCC 2016: 17th International Carpathian Control Conference, pp. 424-428. 2016. DOI:10.1109/CarpathianCC.2016.7501135

[12] M. Laciak, D. Ráškayová. The using of thermodynamic model for the optimal setting of input parameters in the UCG process. In ICCC 2016: 17th International Carpathian Control Conference, pp. 418-423. 2016. DOI:10.1109/CarpathianCC.2016.7501134.

[13] M. Benková, M. Durdán. Statistical analyzes of the underground coal gasification process realized in the laboratory conditions. In SGEM 2016: 16th International Multidisciplinary Scientific GeoConference, Bulgaria Sofia : STEF92 Technology, pp. 405-412. 2016.

[14] Z. Hyder, N. S. Ripepi, M. E. Karmis. A life cycle comparison of greenhouse emissions for power generation from coal mining and underground coal gasification. Mitigation and Adaptation Strategies for Global Change, Springer Netherlands 21(4):515-546, 2014. DOI:10.1007/s11027-014-9561-8.

[15] K. Kostúr, J. Kačur. Indirect measurement of syngas calorific value. In ICCC 2015: 16th International Carpathian Control Conference (ICCC), pp. 418-423. IEEE, 2015. DOI:10.1109/carpathiancc.2015.7145079

[16] G. Perkins, A. Saghafi, W. Sahajwalla. Numerical modelling of underground coal gasification and its application to Australian coal seam conditions. School of Materials Science and Engineering, University of New South Wales, Sydney, Australia, 2001.

[17] J. Balátě. Automatické ř́zení. 2. Přepracované vydání. BEN - technická literatúra, Praha, 2009.

[18] A. Gibb. The Underground Gasification of Coal. Sir Isaac Pitman \& Sons Ltd, London, 1964.

[19] R. F. Chaiken, J. W. Martin. In situ gasification and combustion of coal. SME Mining Engineering Handbook pp. 1954-1970, 1998.

[20] J. Kačur, M. Durdán, M. Laciak, P. Flegner. Impact analysis of the oxidant in the process of underground coal gasification. Measurement 51:147-155, 2014. DOI:10.1016/j.measurement.2014.01.036.

[21] K. Kostúr, M. Laciak, M. Durdán, et al. Low-calorific gasification of underground coal with a higher humidity. Measurement 63:69-80, 2015. DOI:10.1016/j.measurement.2014.12.016.

[22] R. L. Dobbs, W. B. Krantz. Combustion front propagation in underground coal gasification, final report, work performed under grant No. DE-FG22-86PC90512. Technical report, University of Colorado, Boulder Department of Chemical Engineering, 1990.

[23] M. Laciak, K. Kostúr, M. Durdán, et al. The analysis of the underground coal gasification in experimental equipment. Energy 114:332-343, 2016.

DOI:10.1016/j.energy.2016.08.004 
[24] K. Kostúr, et al. Research report of the project "Underground gasification by thermal decomposition no. APVV-0582-06 for year 2008". Technical report, Technical University of Košice, Faculty BERG and HBP a.s. Prievidza, 2008.

[25] K. Kostúr, et al. Research report of the project "Underground gasification by thermal decomposition no. APVV-0582-06 for year 2007". Technical report, Technical University of Košice, Faculty BERG, 2007.

[26] B. Stehlíková, P. Flegner. Possibilities to compare vibration in drilling rocks. In Proceedings of the 2014 15th International Carpathian Control Conference (ICCC). IEEE, 2014. DOI:10.1109/carpathiancc.2014.6843666

[27] T. Sasvári, M. Blištanová, et al. (Eds). Možnosti získavania energetického plynu z uholných ložísk. 1st Ed. Edičné stredisko TU v Košiciach, Faculty BERG, 2007.

[28] L. Dorčák, J. Terpák, F. Dorčáková. Teória automatického riadenia - Spojité lineárne systémy. Edičné stredisko AMS, Faculty BERG, TU v Košiciach, Košice, 2003.

[29] K. Åström, T. Hagglund. PID Controllers: Theory, Design, and Tuning. 2nd Ed. Instrument Society of America, USA, 1995.

[30] V. Bobál, J. Böhm, R. Prokop, J. Fessl. Praktické aspekty samočinne se nastavujicich regulátorú: algoritmy a implementace, 1. Vydání. Vsoké učení technické v Brně, VUTIUM, Brno, 1999.

[31] A. Visioli. Basics of PID control. In Advances in Industrial Control, pp. 1-18. Springer London, 2006. DOI:10.1007/1-84628-586-0_1

[32] C. A. Smith, A. B. Corripio. Principles and practice of automatic process control. John Wiley \& Sons, Inc.; 2nd edition, Danvers, USA, 2008.

[33] V. Bobál, J. Böhm, J. Fessl, J. Macháček. Process modelling and identification for use in self-tuning controllers. In Digital Self-tuning Controllers: Algorithms, Implementation and Applications (Advanced Textbooks in Control and Signal Processing), pp. 21-52.

Springer-Verlag, 2005. DOI:10.1007/1-84628-041-9_3

[34] K. Åström, B. Wittenmark. Computer Controlled Systems - Theory and Design. 3rd Ed. Prentice Hall, New Jersey, USA, 1996.

[35] O. Modrlák. Teória automatického riadenia II. Úvod do diskrétnej parametrickej identifikácie. TU v Liberci, Liberec, 2003.

[36] K. Kostúr, M. Laciak. The development of technology for the underground coal gasification in a laboratory conditions. Metalurgija 47(3):263, 2008.

[37] B. Hanuš, O. Modrlák, M. Olehla. Č́slicová regulace technologických procesư. Algoritmy, matematicko-fyzikálni analýza, identifikace, adaptace, 1. Vydání. Vysoké učení technické v Brňe, VUTIUM, Brno, 2000.
[38] J. Kačur, K. Kostúr. Analysis of algorithms for control time delay systems. In ICCC 200\%: 8th International Carpathian Control Conference, pp. 256-259. 2007.

[39] R. Isermann. Digital Control Systems. Springer-Verlag, Berlin, Heidelberg, 1981. DOI:10.1007/978-3-662-02319-8

[40] O. Davidová. Porovnanie metód syntézy diskrétnych regulačných obvodov. Automa 12:55-60, 2006.

[41] N. B. Nichols, J. G. Ziegler. Optimum settings for automatic controllers. Journal of Dynamic Systems, Measurement and Control, Transactions of the ASME 115(2B):220-222, 1993. DOI:10.1115/1.2899060.

[42] M. Alexík. Modification of dead beat algorithm for control processes with time delay. In 16th Triennial World Congress of International Federation of Automatic Control, IFAC 2005, Prague; Czech Republic, Vol. 38, pp. 278-283. 2005. DOI:10.3182/20050703-6-cz-1902.00617.

[43] K. Kostúr, J. Kačur. Developing of optimal control system for UCG. In Proceedings of the 13th International Carpathian Control Conference (ICCC). IEEE, 2012. DOI:10.1109/carpathiancc.2012.6228666

[44] J. Kačur, K. Kostúr. The algorithms for control of heating massive material. Acta Montanistica Slovaca 13(1):87-93, 2008. http:

//actamont.tuke.sk/pdf/2008/n1/12kacur.pdf

[45] J. Kačur, M. Durdán, G. Bogdanovská. Monitoring and measurement of the process variable in UCG. In $S G E M$ 2016: 16th International Multidisciplinary Scientific GeoConference, Bulgaria - Sofia : STEF92 Technology, pp. 295-302. 2016.

[46] M. Koenen, F. Bergen, P. David. Isotope measurements as a proxy for optimising future hydrogen production in underground coal gasification, news in depth, 2015. https: //www.tno.nl/media/2624/information20-nid1.pdf

[47] H. S. Wu. The measuring methods of Radon and its application. Beijing: Nuclear Energy Press, 1995.

[48] M. Durdán, K. Kostúr. Modeling of temperatures by using the algorithm of queue burning movement in the UCG process. Acta Montanistica Slovaca 20(3):181-191, 2015. http:

//actamont.tuke.sk/pdf/2015/n3/3durdan.pdf

[49] M. Durdán, J. Kačur. Indirect temperatures measurement in the UCG process. In Proceedings of the 14 th International Carpathian Control Conference (ICCC). IEEE, 2013. DOI:10.1109/carpathiancc.2013.6560514

[50] J. M. Wu. Radon distribution under the mine and the application of radon measuring in the monitoring of the natural fire zone, 1994.

[51] H. S. Wu. The transferring effects of radon moving. Geophysics Journal 14(1):136, 1995.

[52] India SME Technology Services Ltd. 15 Variable Water requirement with VFD. http:

//www.techsmall.com/eAdmin/knowledgebankfile/ EE $\% 20$ in $\% 20$ Pump $\% 20$ through $\% 20$ auto $\% 20$ control.pdf 